OPEN ACCESS

Edited by:

Claire Colas,

University of Vienna, Austria

Reviewed by

Ekaitz Errasti Murugarren,

Institute for Research in

Biomedicine, Spain

Cesare Indiveri,

University of Calabria, Italy

*Correspondence:

Camila A. Cotrim

c.cotrim@uea.ac.uk

David Drew

david.drew@dbb.su.se

Jennifer L. Martin

jlm@griffith.edu.au

${ }^{\dagger}$ Present address:

Camila A. Cotrim

Biomedical Research Centre, Norwich Medical School, University of East Anglia, Norwich, United Kingdom

Hassanul G. Choudhury, Cello Health Consulting, Farnham,

Surrey, United Kingdom

Specialty section:

This article was submitted to

Chemical Biology,

a section of the journal

Frontiers in Chemistry

Received: 14 February 2021 Accepted: 31 March 2021

Published: 30 April 2021

Citation:

Cotrim $C A$, Jarrott RJ, Whitten $A E$, Choudhury HG, Drew D and Martin JL (2021) Heterologous Expression and

Biochemical Characterization of the Human Zinc Transporter 1 (ZnT1) and

Its Soluble C-Terminal Domain.

Front. Chem. 9:667803.

doi: $10.3389 /$ fchem.2021.667803

\section{Heterologous Expression and Biochemical Characterization of the Human Zinc Transporter 1 (ZnT1) and Its Soluble C-Terminal Domain}

\author{
Camila A. Cotrim ${ }^{1 *}$, Russell J. Jarrott ${ }^{1}$, Andrew E. Whitten ${ }^{2}$, Hassanul G. Choudhury ${ }^{3 \dagger}$, \\ David Drew ${ }^{4 *}$ and Jennifer L. Martin ${ }^{1,5 *}$
}

${ }^{1}$ Griffith Institute for Drug Discovery, Griffith University, Nathan, QLD, Australia, ${ }^{2}$ Australian Nuclear Science and Technology Organisation, Lucas Heights, NSW, Australia, ${ }^{3}$ Institute for Molecular Bioscience, University of Queensland, St Lucia, QLD, Australia, ${ }^{4}$ Department of Biochemistry and Biophysics, Stockholm University, Stockholm, Sweden, ${ }^{5}$ Vice-Chancellor's Unit, University of Wollongong, Wollongong, NSW, Australia

Human zinc transporter 1 (hZnT1) belongs to the cation diffusion facilitator (CDF) family. It plays a major role in transporting zinc $\left(\mathrm{Zn}^{2+}\right)$ from the cytoplasm across the plasma membrane and into the extracellular space thereby protecting cells from $\mathrm{Zn}^{2+}$ toxicity. Through homology with other CDF family members, ZnT1 is predicted to contain a transmembrane region and a soluble C-terminal domain though little is known about its biochemistry. Here, we demonstrate that human ZnT1 and a variant can be produced by heterologous expression in Saccharomyces cerevisiae cells and purified in the presence of detergent and cholesteryl hemisuccinate. We show that the purified hZnT1 variant has $\mathrm{Zn}^{2+} / \mathrm{H}^{+}$antiporter activity. Furthermore, we expressed, purified and characterized the soluble C-terminal domain of hZnT1 (hZnT1-CTD) in a bacterial expression system. We found that the hZnT1-CTD melting temperature increases at acidic $\mathrm{pH}$, thus, we used an acetate buffer at $\mathrm{pH} 4.5$ for purifications and concentration of the protein up to $12 \mathrm{mg} / \mathrm{mL}$. Small-angle X-ray scattering analysis of hZnT1-CTD is consistent with the formation of a dimer in solution with a V-shaped core.

Keywords: human zinc transporter 1, cation diffusion facilitator, C-terminal domain, small-angle X-ray scattering, membrane proteins

\section{INTRODUCTION}

Zinc $\left(\mathrm{Zn}^{2+}\right)$ plays an important role in many key biological processes, such as immune function, redox signaling, and cell death (Vallee and Falchuk, 1993). Conversely, $\mathrm{Zn}^{2+}$ dysregulation can lead to chronic inflammation, growth retardation or metabolic disorders (Prasad, 2013). Moreover, $\mathrm{Zn}^{2+}$ has been associated with other medical conditions, including diabetes, Alzheimer's disease and transient neonatal zinc deficiency (TNZD) (Lovell et al., 2005; Chowanadisai et al., 2006; Sladek et al., 2007). High levels of $\mathrm{Zn}^{2+}$ are toxic and tight regulation of intracellular $\mathrm{Zn}^{2+}$ concentrations is essential to maintain good health (Huang and Tepaamorndech, 2013). In mammals, physiological $\mathrm{Zn}^{2+}$ levels are regulated by the action of three classes of proteins: metallothioneins (MTs); ZRT/IRT-like protein (ZIPs) and cation diffusion facilitators (CDF) (Blindauer, 2015; Kolaj-Robin et al., 2015). MTs bind free $\mathrm{Zn}^{2+}$ ions directly (Kimura and Kambe, 2016), whereas CDF and ZIP proteins regulate intracellular $\mathrm{Zn}^{2+}$ levels by sequestration and recruitment from organelles or the extracellular environment (Huang and Tepaamorndech, 2013). 
In mammals, the zinc transporter CDF family members are referred to as $\mathrm{ZnT}$ or solute carrier family 30 (SLC30A). To date, ten members of the ZnT family (ZnT1 - ZnT10) have been identified (Huang and Tepaamorndech, 2013). Predicted structures of eukaryotic ZnT transporters have been reported on the basis of the crystal structure and cryo-EM structures of Escherichia coli YiiP (EcYiiP) (Lu and Fu, 2007) and Shewanella oneidensis YiiP (SoYiiP) (Coudray et al., 2013; Lopez-Redondo et al., 2018). Recently, cryo-EM structures of human ZnT8 (hZnT8) in different conformations were reported (Xue et al., 2020) revealing its overall structure and shedding light on its mechanism of action. As observed for the bacterial zinc transporter YiiP structures, hZnT8 forms a Y-shaped homodimer with two domains: a transmembrane domain (TMD) comprising six transmembrane helices, and a cytosolic C-terminal domain (CTD) (Lu and Fu, 2007; Lu et al., 2009; Coudray et al., 2013; Lopez-Redondo et al., 2018; Xue et al., 2020). Several CDF proteins have been described as antiporters, catalyzing active efflux of metals $\left(\mathrm{M}^{2+}\right)$ by a proton-motive force in exchange for $\mathrm{H}^{+}$or $\mathrm{K}^{+}$(Guffanti et al., 2002; Chao and $\mathrm{Fu}, 2004$; Ohana et al., 2009; Shusterman et al., 2014). The transport mechanism of individual CDF members has included divergent mechanisms, such as scissoring and alternating-access models (see Cotrim et al., 2019, for review). The recent hZnT8 structures in the outward- and inward-facing conformations suggest a simple twostate model of $\mathrm{Zn}^{2+}$ transport, as no occluded state has been reported in the structural analysis (Xue et al., 2020).

Among ZnT members, ZnT1 is the most ubiquitously expressed and the only member localized to the plasma membrane (Palmiter and Findley, 1995; Qin et al., 2009), where it plays a pivotal role in zinc homeostasis by conferring resistance against zinc toxicity (Palmiter and Findley, 1995). Previous studies have suggested that $\mathrm{ZnT} 1$ is essential to embryonic development, as knockout of the SLC30A1 gene in mice is lethal during early embryogenesis (Langmade et al., 2000; Andrews et al., 2004). Furthermore, altered expression levels of SLC30A1 have been linked to Alzheimer's disease and different types of cancers (Lovell et al., 2005; Jing et al., 2018). A recent study also suggested that altered expression of ZnT1 may contribute to prooncogenic processes and cancer progression (Lehvy et al., 2019). In addition to its function as a zinc transporter, ZnT1 acts as a negative regulator of the L-type calcium channel (LTCC) through its interaction with the $\beta_{2 a}$-subunit of voltage-gated calcium channels (Segal et al., 2004; Levy et al., 2009). Recent studies have also demonstrated that the soluble C-terminal domain (CTD) of ZnT1 interacts with Raf-1 kinase leading to activation of the Ras-Raf-ERK signaling pathway, which in turn may promote a cardioprotective effect from ischemia-reperfusion (Jirakulaporn and Muslin, 2004; Beharier et al., 2012).

Although the cellular importance of ZnT1 has been widely investigated, little is known about its biochemical features. In this study, we investigated the production of human ZnT1 (hZnT1) recombinantly expressed in Saccharomyces cerevisiae. Our results indicate that full-length and a truncated form of hZnT1 can be produced in yeast and that protein extraction in the presence of detergent incorporated with cholesteryl hemisuccinate generates active protein. We also expressed, purified and investigated the soluble CTD of human ZnT1 (hZnT1-CTD) by small-angle Xray scattering (SAXS), showing that it forms dimers in solution. Taken together, our results provide the basis for further structural investigations of $\mathrm{ZnT}$ proteins.

\section{MATERIALS AND METHODS}

\section{Protein Expression}

\section{Protein Expression in Yeast Cells}

We used a variant of human ZnT1 in which Asn99 (potential glycosylation site) was replaced with Gln. We worked with two constructs, both codon-optimized for $S$. cerevisiae expression: hZnT1 [see Supplementary Note 1 in Supplementary Material for sequence (GenScript)] and $\mathrm{hZnT1 \Delta C}$. The latter construct was designed to remove C-terminal regions between Glu420Pro432 and Gln440-Leu507 that were predicted to be highly disordered. Both constructs were inserted into a modified pDDGFP-2 vector (Newstead et al., 2007) (encoding Cterminal His- and Strep-tags) by homologous recombination in S. cerevisiae strain FGY217 (MAT $\alpha$, ura3-52, lys2 $\Delta 201$ and pep4 $\Delta$ ) (Kota et al., 2007; Drew et al., 2008) (Figure 1A) (see Supplementary Table 1 for list of primers). hZnT1 and $\mathrm{hZnT1 \Delta C}$ were expressed in S. cerevisiae FGY217 in -URA selective medium containing $0.1 \%(\mathrm{w} / \mathrm{v})$ glucose (Drew et al., 2008). Cells were grown at $30^{\circ} \mathrm{C}$ till $\mathrm{OD}_{600} 0.6$ and protein expression was induced by $2 \%(\mathrm{w} / \mathrm{v})$ galactose for $22 \mathrm{~h}$ at $30^{\circ} \mathrm{C}$. After expression, cells were harvested by centrifugation (Sorvall SuperLynx, Thermo Fisher Scientific), resuspended in CRB buffer (50 mM Tris- $\mathrm{HCl} \mathrm{pH}$ 7.6, $1 \mathrm{mM}$ EDTA, 0.6 M sorbitol), frozen and stored at $-80^{\circ} \mathrm{C}$.

For membrane fraction preparation, cells were lysed by mechanical disruption and unbroken cells and debris were removed by centrifugation at $10,000 \mathrm{~g}$ at $4^{\circ} \mathrm{C}$ for $10 \mathrm{~min}$. Membranes were then isolated at $4^{\circ} \mathrm{C}$ by ultracentrifugation (Sorvall WX+ ultracentrifuge, Thermo Fisher Scientific) at $125,000 \mathrm{~g}$ for $2 \mathrm{~h}$ (Drew et al., 2008). The membrane was resuspended in $20 \mathrm{mM}$ Tris- $\mathrm{HCl} \mathrm{pH} 7.5,0.3 \mathrm{M}$ sucrose, $0.1 \mathrm{mM}$ $\mathrm{CaCl}_{2}$ in a ratio of $3.5 \mathrm{~mL}$ buffer per liter of expression and stored at $-80^{\circ} \mathrm{C}$.

\section{Protein Production in Bacteria Cells}

For cloning of the C-terminal soluble domain (hZnT1-CTD), the codon-optimized gene sequence (GenScript) encoding residues 342-507 was amplified and cloned into a pET24a

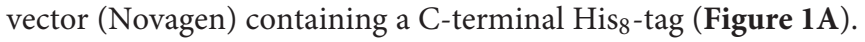
hZnT1-CTD was expressed in Rosetta-gami (DE3) cells at $30^{\circ} \mathrm{C}$ for 22-24h using autoinduction (Studier, 2005) supplemented with $20 \mu \mathrm{M} \mathrm{ZnCl}$. After expression, cells were harvested by centrifugation (Sorvall SuperLynx, Thermo Fisher Scientific) and the pellet stored at $-80^{\circ} \mathrm{C}$.

\section{Detergent Screening and FSEC Analysis}

All detergents were obtained from Anatrace, unless otherwise stated. hZnT1 membrane was examined to measure the extraction efficiency of the following detergents: 6-cyclohexyl-1-hexyl- $\beta$-D-maltoside (Cymal-6), n-dodecyl$\beta$-D-maltopyranoside (DDM), decyl- $\beta$-D-maltopyranoside 
A
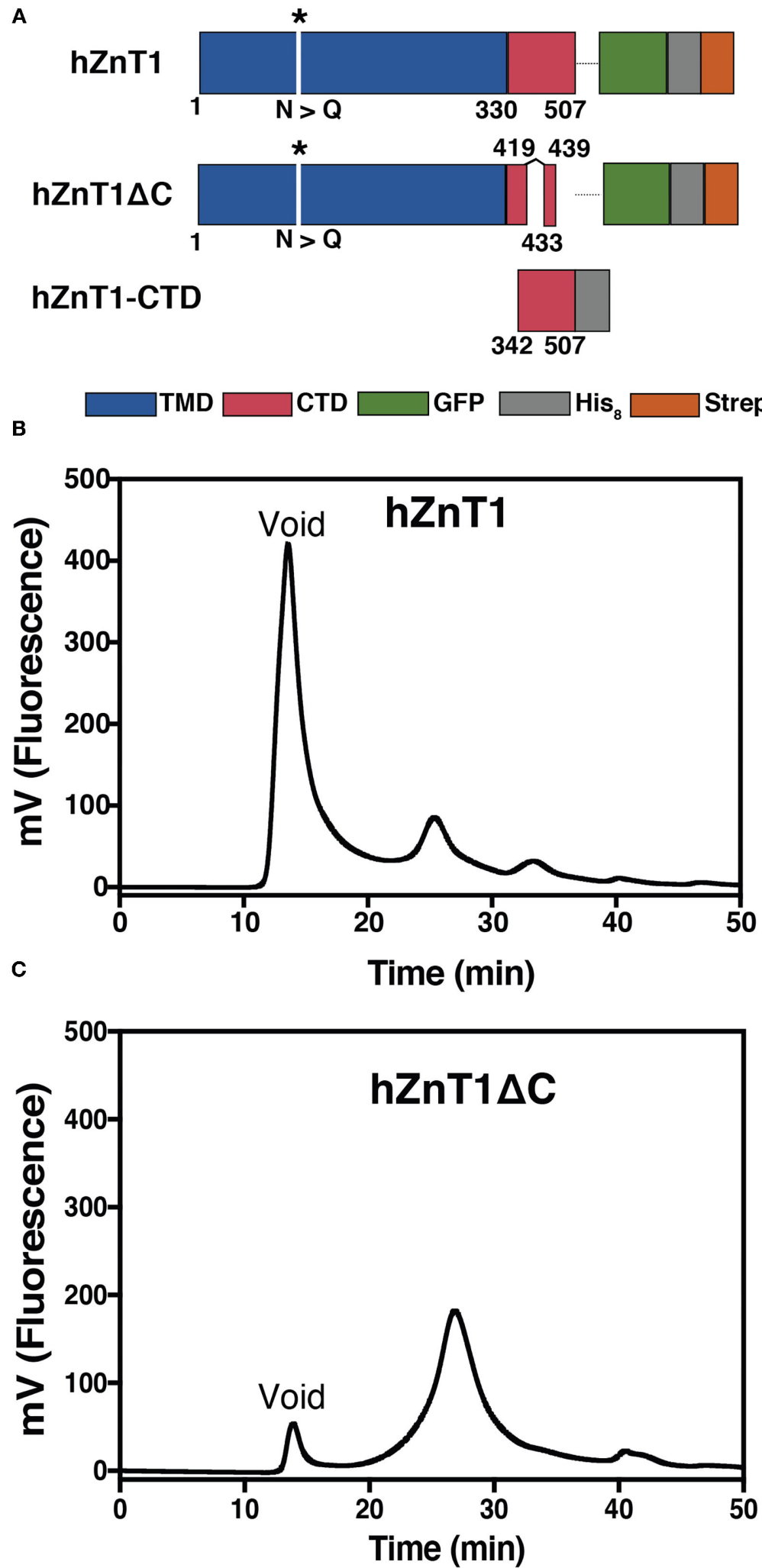

FIGURE 1 | Production of hZnT1 and hZnT1 $\Delta$ C. (A) Linear representation of the constructs. Transmembrane domain is colored in blue, the soluble C-terminal domain (CTD) in red, with the white spaces indicating regions that were truncated. GFP is shown in green and the His 8 and Strep tags are shown in gray and orange, 
FIGURE 1 | respectively. The asterisk indicates mutation of N99Q. (B) Fluorescence size exclusion chromatography (FSEC) profile of purified hZnT1. (C) hZnT1 $\Delta \mathrm{C}$ optimized FSEC profile. Profiles based on GFP fluorescence. Wavelengths: $488 \mathrm{~nm}$ (excitation); $512 \mathrm{~nm}$ (emission). Column: Superose 6 ; flow: $0.5 \mathrm{~mL} / \mathrm{min}$; buffer: $20 \mathrm{mM}$ Tris- $\mathrm{HCl} \mathrm{pH} 7.6,150 \mathrm{mM} \mathrm{NaCl}, 0.03 \%$ DDM.

(DM), lauryldimethylamine oxide (LDAO), neopentyl glycol (NG), n-nonyl- $\beta$-D-maltopyranoside (NM), n-octyl- $\beta$-Dglucopyranoside $(\beta-\mathrm{OG})$, decyl glucose neopentyl glycol (DGNG) and lauryl maltose neopentyl glycol (LMNG). A stock solution of each detergent $(10 \%(\mathrm{w} / \mathrm{v}))$ was mixed with $500 \mu \mathrm{L}$ membrane to a final concentration of $1 \%(\mathrm{w} / \mathrm{v})$ and incubated under mild agitation for $1 \mathrm{~h}$ at $4^{\circ} \mathrm{C}$. Samples were centrifuged (Optima $^{\text {TM }}$ Max-XP ultracentrifuge, Beckman Coulter) at $112,000 \mathrm{~g}$ for $15 \mathrm{~min}$ to remove insolubilized material. The supernatant (containing solubilized protein) was analyzed by fluorescence size exclusion chromatography (FSEC) (Kawate and Gouaux, 2006). FSEC was carried out using an ÄKTA Purifier system (GE Healthcare) with a fluorescence detector attached (Jasco FP 2020 Plus). Samples were injected into a Superose 6 $10 / 300$ column pre-equilibrated with FSEC buffer (20 mM Tris $\mathrm{pH} 7.6,150 \mathrm{mM} \mathrm{NaCl}$ and 0.03\% DDM).

\section{GFP-Based Thermal Shift Assay for hZnT1 and $\mathrm{hZnT1} \Delta \mathrm{C}$ Proteins}

Melting curves for hZnT1 and hZnT1 $\Delta \mathrm{C}$ were determined according to $\mathrm{Nji}$ et al. (2018). Membranes were solubilized in buffer containing $20 \mathrm{mM}$ Tris- $\mathrm{HCl} \mathrm{pH} 7.6,150 \mathrm{mM} \mathrm{NaCl}$, and $1 \%(\mathrm{w} / \mathrm{v})$ DDM or LMNG in the presence or absence of cholesteryl hemisuccinate (CHS) for $1 \mathrm{~h}$ at $4^{\circ} \mathrm{C}$ under mild agitation. After solubilization, $10 \%(\mathrm{w} / \mathrm{v}) \beta$-OG was added to the solubilized membrane [to a final concentration of $1 \%(\mathrm{w} / \mathrm{v})$ ] and $150 \mu \mathrm{L}$ of the solution transferred into $1.5 \mathrm{~mL}$ tubes for 10 min incubation at $4,20,30,40,50,60,70,80$, and $100^{\circ} \mathrm{C}$ using a Thermomixer (Eppendorf). Samples were centrifuged at $14,000 \mathrm{~g}$ (Microfuge 22R, Beckman Coulter) for $30 \mathrm{~min}$ at $4^{\circ} \mathrm{C}$ and supernatant transferred into a black Nunc 96-well optical bottom plate for measurement of GFP fluorescence. The apparent $\mathrm{T}_{m}$ was calculated by plotting the average GFP fluorescence intensity (RFU) and fitting the curves to a sigmoidal doseresponse equation by GraphPad Prism software. Three technical repeats were used, with goodness of the fit $>0.98$.

\section{Protein Purification}

Isolated membranes from large scale expression (36L) of $S$. cerevisiae culture harboring overexpressed GFP-fusion proteins (hZnT1 and hZnT1 $\Delta$ C) were solubilized in buffer containing PBS, $150 \mathrm{mM} \mathrm{NaCl}, 10 \%(\mathrm{v} / \mathrm{v})$ glycerol and 2\%:0.4\% (w/v) DDM:CHS for $90 \mathrm{~min}$ at $4^{\circ} \mathrm{C}$ with gentle agitation. After solubilization the samples were clarified by ultracentrifugation $\left(100,000 \mathrm{~g}, 60 \mathrm{~min}, 4^{\circ} \mathrm{C}\right)$ to remove unsolubilized material. The supernatant was incubated with $5 \mathrm{~mL}$ Strep-Tactin Sepharose resin (50\% suspension, IBA life sciences) for $2 \mathrm{~h}$ at $4^{\circ} \mathrm{C}$ under mild agitation. The resin was transferred to a $30 \mathrm{~mL}$ Econo-column (BioRad) and washed with 20 column volumes (cv) of buffer containing PBS, $500 \mathrm{mM} \mathrm{NaCl}, 10 \% \quad(\mathrm{v} / \mathrm{v})$ glycerol; 0.03\%:0.006\% (w/v) DDM:CHS. The protein was eluted with buffer containing $100 \mathrm{mM}$ Tris- $\mathrm{HCl}$ pH 8.0, $150 \mathrm{mM}$ $\mathrm{NaCl}, 0.03 \%: 0.006 \%$ (w/v) DDM:CHS, $1 \mathrm{mM}$ EDTA, $50 \mathrm{mM}$ biotin and elution fractions were monitored based on GFP fluorescence. Pooled fractions were further purified by sizeexclusion chromatography using a Superdex 200 16/600 column pre-equilibrated with $20 \mathrm{mM}$ Tris- $\mathrm{HCl}$ pH 7.6, $150 \mathrm{mM} \mathrm{NaCl}$, 0.01\%:0.002\% (w/v) DDM:CHS connected to an ÄKTA Purifier system (GE Healthcare). Proteins were concentrated using Amicon Ultra centrifugal filter devices with a $100-\mathrm{kDa}$ cutoff (Merck Millipore). Protein purity was analyzed by SDS-PAGE with Coomassie blue stain.

Isolated pellet from $2 \mathrm{~L}$ of Rosetta-gami (DE3) culture harboring hZnT1-CTD was resuspended in $600 \mathrm{~mL}$ lysis buffer (25 mM Tris- $\mathrm{HCl} \mathrm{pH} 7.6,300 \mathrm{mM} \mathrm{NaCl}, 10 \%$ (v/v) glycerol, $10 \mathrm{mM}$ imidazole, $1 \%$ (v/v) Triton X-100, $3.3 \mathrm{mg}$ DNase, $0.4 \mathrm{mg}$ lysozyme) and sonicated for $2 \mathrm{~min}, 100 \%$ duty cycle at $20-40 \mathrm{~Hz}$ for 3 cycles (Branson Sonicator) at $4^{\circ} \mathrm{C}$. Lysate was clarified by centrifugation $\left(28,000 \mathrm{~g}, 30 \mathrm{~min}, 4^{\circ} \mathrm{C}\right)$ and supernatant was incubated with $3 \mathrm{~g}$ PrepEase metal affinity resin (USB Corporation) for $2 \mathrm{~h}$ under agitation at $4^{\circ} \mathrm{C}$. Supernatant-resin suspension was poured through Econo-columns (BioRad) and washed with $200 \mathrm{~mL}$ wash buffer 1 [25 mM Tris- $\mathrm{HCl} \mathrm{pH} \mathrm{7.6,}$ $300 \mathrm{mM} \mathrm{NaCl}, 10 \%$ (v/v) glycerol, $20 \mathrm{mM}$ imidazole, $1 \mathrm{mM}$ Tris (2-carboxyethyl)phosphine hydrochloride (TCEP)] and $200 \mathrm{~mL}$ wash buffer 2 (wash buffer 1 containing $40 \mathrm{mM}$ imidazole). Protein was eluted in $25 \mathrm{mM}$ Tris- $\mathrm{HCl} \mathrm{pH}$ 7.6, $300 \mathrm{mM} \mathrm{NaCl}$, $10 \%(\mathrm{v} / \mathrm{v})$ glycerol, $500 \mathrm{mM}$ imidazole, $1 \mathrm{mM}$ TCEP and further purified by size exclusion chromatography (SEC) in a Superdex 200 16/600 column (GE Healthcare) equilibrated with buffer A $\left(25 \mathrm{mM} \mathrm{CH}_{3} \mathrm{COONa} \mathrm{pH} 4.5,100 \mathrm{mM} \mathrm{NaCl}, 0.5 \mathrm{mM}\right.$ TCEP, $20 \mu \mathrm{M} \mathrm{ZnCl}_{2}$ ). The final purification step was carried out in a Mono $\mathrm{Q}$ column (GE Healthcare) with a salt gradient of $0 \%$ to $100 \%$ buffer $B$ (buffer A containing $1 \mathrm{M} \mathrm{NaCl}$ ). Fractions containing hZnT1-CTD (flow through) were pooled and concentrated as required for subsequent assays.

\section{Lipid Screening of Purified hZnT1 $\Delta \mathrm{C}$}

Lipid screening for purified $\mathrm{hZnT} 1 \Delta \mathrm{C}$ was carried out according to $\mathrm{Nji}$ et al. (2018). Briefly, to $96 \mu \mathrm{L}$ of purified protein (0.1 to $0.3 \mathrm{mg} / \mathrm{mL}), 12 \mu \mathrm{L}$ of the following lipids were added to a final concentration of $3 \mathrm{mg} / \mathrm{mL}$ : DOPC (Avanti), DOPG (Avanti), DOPE (Avanti), monoolein (Anatrace), cholesteryl hemisuccinate (CHS) (Sigma), brain lipids (Sigma), sphingomyelin (Avanti), bovine lipids (Avanti), E. coli total lipids (Avanti). Stock solutions of lipids were prepared to a final concentration of $30 \mathrm{mg} \mathrm{mL}^{-1}$ by solubilization in $10 \%(\mathrm{w} / \mathrm{v})$ DDM overnight at $4{ }^{\circ} \mathrm{C}$. $\beta$-OG $(10 \%(\mathrm{w} / \mathrm{v})$ stock $)$ was also added to the mixture to a final concentration of $1 \%(\mathrm{w} / \mathrm{v})$. The samples were heated for $10 \mathrm{~min}$ at a temperature $5^{\circ} \mathrm{C}$ higher than the apparent $\mathrm{T}_{m}$ and then centrifuged at $14,000 \mathrm{~g}$ at $4^{\circ} \mathrm{C}$ (Microfuge 
22R, Beckman Coulter). The supernatant was collected and GFP fluorescence was measured as previously described.

\section{Crystallization of hZnT1 Variants}

Crystallization screening of hZnT1 variants was performed at the UQ ROCX facility at the University of Queensland (https://cmm.center.uq.edu.au/uq-rocx) using the hanging drop vapor diffusion technique. Crystallization plates for hZnT1 and $\mathrm{hZnT} 1 \Delta \mathrm{C}$ were set up with drops of $200 \mathrm{~nL}$ protein and 200 $\mathrm{nL}$ reservoir solution using a Mosquito robot (TTP Labtech) in 96-well plates. The following commercial kits designed for membrane proteins were used: MemGold1, MemGold2, MemStart/MemSys and MemMeso. The plates were incubated at $22^{\circ} \mathrm{C}$. Protein concentrations varied from 5 to $15 \mathrm{mg} / \mathrm{mL}$. Crystals were harvested from the plates and cryo-protected with $20 \%(\mathrm{v} / \mathrm{v})$ ethylene glycol before flash frozen in liquid nitrogen. Crystal diffraction was assessed on beamline MX2 at the Australian Synchrotron.

hZnT1-CTD crystallization screening was carried out using the hanging drop vapor diffusion technique at $22^{\circ} \mathrm{C}$. The following commercial kits were used: Hampton Research Index HT, Molecular Dimensions JCSG+, ShotgunEco, Molecular Dimensions PACT+, Molecular Dimensions ProPlex and an inhouse Combination screen $(\mathrm{pH}$ and concentration gradient using sodium malonate, ammonium sulfate, sodium chloride, lithium chloride/PEG 6000 plus buffers as required). Protein concentrations varied from 3 to $12 \mathrm{mg} / \mathrm{mL}$.

\section{Protein Thermostability Assay}

A master mix plate consisting of 42 buffers, salts, metals and additives with 6 controls was established (Supplementary Table 2). Purified hZnT1-CTD (1.0 mg/mL) was incubated with 8-fold Protein Thermal Shift Dye (Applied Biosystems, Life Technologies) for $30 \mathrm{~min}$ at $4^{\circ} \mathrm{C}$. Using a 384 well plate (MicroAmp Optical, Applied Biosystems), $10 \mu \mathrm{L}$ of each condition was aliquoted into every second well and $10 \mu \mathrm{L}$ of dye:protein was added and mixed. Samples were analyzed in a QuantStudio 6 Flex (Applied Biosystems) and the instrument software was set to increase the temperature from 25 to $99^{\circ} \mathrm{C}$ with a heating rate of $0.05^{\circ} \mathrm{C} / \mathrm{s}$. Fluorescence intensity was measured with Excitation/Emission: 580/623 nm.

Protein unfolding profiles were analyzed using the Protein Thermal Shift software v1.3 (Applied Biosystems), and the peak in the derivative of the fluorescence signal as a function of temperature, the "melt" temperature $\left(\mathrm{T}_{m}\right)$, provided a relative measure of protein stability.

\section{Coupled Proton Transport Assay Using $\mathrm{hZnT1} \Delta \mathrm{C}$ and $E$. coli ATP Synthase}

Liposome preparation and protein reconstitution were carried out as previously described (Uzdavinys et al., 2017). Briefly, L- $\alpha$-phosphatidylcholine lipids from soybean (type II, Sigma) and brain lipids (type I, Sigma) (ratio 1:1) were mixed in buffer containing $10 \mathrm{mM}$ MOPS pH 6.5, $5 \mathrm{mM} \mathrm{MgCl}_{2}, 100 \mathrm{mM}$ $\mathrm{KCl}$ to a final concentration of $10 \mathrm{mg} / \mathrm{mL}$ and vortexed until homogenized. Lipids were flash-frozen in liquid nitrogen and thawed in a total of eight cycles before extrusion using polycarbonate filters (Whatman) with a pore size of $200 \mathrm{~nm}$. For reconstitution, $250 \mu \mathrm{L}$ of liposomes were destabilized by addition of sodium cholate $[0.65 \%(\mathrm{w} / \mathrm{v})$ final concentration] and mixed with $100 \mu \mathrm{g}$ of both hZnT1 $\Delta \mathrm{C}$ and $\mathrm{F}_{0} \mathrm{~F}_{1}$ ATP synthase from E. coli and incubated for $30 \mathrm{~min}$ at room temperature. Detergent was removed using a PD-10 desalting column (GE Healthcare) and the sample collected in $2.3 \mathrm{~mL}$. For the assay, $100 \mu \mathrm{L}$ of the proteoliposomes containing $\mathrm{hZnT} 1 \Delta \mathrm{C}$ and ATP synthase were diluted into $1.5 \mathrm{~mL}$ of working buffer (MOPS buffer, $\mathrm{pH}$ 6.5) containing $2.5 \mathrm{nM}$ ACMA (9amino-6-chloro-2-methoxyacridine, Thermo Fisher Scientific) and $130 \mathrm{nM}$ valinomycin (Sigma). Proton influx was established by the addition of $130 \mu \mathrm{M}$ ATP, as detected by a change in ACMA fluorescence (488 $\mathrm{nm}$ excitation; $410 \mathrm{~nm}$ emission). After $1 \mathrm{~min}$ equilibration, the activity of $\mathrm{hZnT} 1 \Delta \mathrm{C}$ was assessed by addition of $10 \mathrm{mM} \mathrm{ZnCl}$. The reaction was stopped with addition of $\mathrm{NH}_{4} \mathrm{Cl}$ (20 mM final concentration).

\section{Small-Angle X-Ray Scattering (SAXS) Analysis}

SAXS data for hZnT1-CTD was collected on the SAXS-WAXS beamline at the Australian Synchrotron using an in-line SECSAXS sheath flow set-up (Supplementary Table 3) (Kirby et al., 2013, 2016). Data reduction was carried out using Scatterbrain software (v 2.71) (Software for acquiring, processing and viewing SAXS/WAXS data at the Australian Synchrotron), and corrected for solvent scattering and sample transmission. Contrast and partial specific volumes were determined from the protein sequences (Whitten et al., 2008), while the molecular mass was estimated from the Porod volume (Fischer et al., 2010). Data processing and Guinier analysis was performed using Primus (Konarev et al., 2003) (v 3.2). The pair-distance distribution function $[p(r)]$ was generated from the experimental data using GNOM (v 4.6) (Svergun, 1992), from which $I(0), R_{\mathrm{g}}$ and $D_{\max }$ were determined. The program DAMMIN (v 5.3) (Svergun, 1999) was used to generate 16 dummy-atom models for each protein, assuming a prolate geometry with long axis perpendicular to the $C_{2}$ symmetry axis. Of the 16 dummy-atom models generated, 15 were averaged using the program DAMAVER ( $\mathrm{v} 2.8 .0$ ) (Volkov and Svergun, 2003) preserving the $C_{2}$ symmetry, and the resolution of the averaged structure estimated using SASRES (Tuukkanen et al., 2016). The program CORAL (v 1.1) was used to generate 16 rigid-body models assuming a dimeric structure with $C_{2}$ symmetry (Petoukhov et al., 2012). For the rigid-body modeling, the initial structure of hZnT1-CTD (residues 342507) was generated using iTasser (Yang et al., 2014), where the $\mathrm{N}$-terminal portion $(342-422)$ is found to be similar to other homologous proteins (such as PDB ID: 3BYR), but the Cterminal portion (432-498) was predicted to be predominantly coil as there are no templates with a similar sequence that can be used to predict the structure. The two subunits were modeled with a nine residue flexible linker, and a nine residue flexible region was included at the C-terminus. A distance restraint of $10 \AA$ between T53 in one protein of the complex and Y55 was included to force dimerization through the $\mathrm{N}$-terminal domain in a similar manner to that observed in homologous structures. The 
chosen rigid-body showed the best overall fit $\left(\chi^{2}=1.27\right)$. Data has been deposited in the SASBDB with accession ID: SASDJ85.

\section{RESULTS AND DISCUSSION}

\section{hZnT1 and hZnT1 $\triangle \mathrm{C}$ Can Be Heterologously Expressed in S. cerevisiae}

Initial expression screening of hZnT1 showed strong GFP fluorescence indicative of good expression levels. However, fluorescence size exclusion chromatography (FSEC) analysis of the protein after DDM solubilization suggested protein aggregation (high peak at the void volume of the column, Figure 1B). Detergent screening was performed to identify whether other detergents might preserve ZnT1 integrity. However, all the detergents tested had a large aggregate peak at void volume $(\sim 8 \mathrm{~mL})$ and a much smaller fluorescence peak (presumably corresponding to hZnT1) at $\sim 11-13 \mathrm{~mL}$ (Supplementary Figure 1). Because there was little difference in the profiles, we chose to proceed with two mild detergents (Stetsenko and Guskov, 2017), DDM and LMNG, for large scale purifications.

Disordered regions are flexible parts of a protein that can inhibit crystallization (Deller et al., 2016). Sequence analysis using the Protein Disorder Prediction System (PrDOS) server (Ishida and Kinoshita, 2007) identified several regions predicted to be disordered in hZnT1. These include the cytosolic His-rich domain, from residues Gly139 to Asn244, and regions in the C-terminal domain (Glu419 to Leu507, Supplementary Figure $2 \mathrm{~A}$ ). The $\mathrm{hZnT} 1 \Delta \mathrm{C}$ variant, removes disordered regions in the CTD from Glu420 to Pro432 and from Gln440 to Leu507 (Figure 1A). The His-rich region in the TMD was not truncated, as it has been associated with zinc binding (Kawachi et al., 2008; Podar et al., 2012) and modulation of zinc transport activity (Fukue et al., 2018). Expression of hZnT1 $\Delta \mathrm{C}$ in yeast yielded an improved FSEC profile after solubilization in DDM, with a much reduced void volume peak (Figure 1C). Several attempts were made to remove the GFP tag for protein characterization, but the yield after this step was very low. Characterization of both hZnT1 and hZnT1 $\Delta \mathrm{C}$ proteins was therefore carried out in the presence of the GFP fusion tag. Using this approach, purification of either hZnT1 or hZnT1 $\Delta \mathrm{C}$ from a $36 \mathrm{~L}$ pellet using a two-step method (Strep-Tactin Sepharose resin followed by SEC) was reproducible and yielded $\sim 1.5 \mathrm{mg}$ and $2 \mathrm{mg}$ of protein, respectively (Supplementary Figure 3 ).

\section{hZnT1 Can Be Stabilized by CHS and Lipids}

Obtaining folded protein is a key challenge when producing eukaryotic membrane proteins in unicellular organisms. S. cerevisiae cells have been used successfully for the production of active membrane proteins for both functional and structural characterization (Jidenko et al., 2005; Nomura et al., 2015; Schütz et al., 2016). This organism offers the simplicity of a unicellular system and lower costs in comparison to mammalian cell lines, and can provide some post-translation modifications (Vieira Gomes et al., 2018). However, S. cerevisiae membranes lack cholesterol, which can be essential for stability of eukaryotic membrane proteins (Singh, 2017). Several studies have demonstrated that cholesterol analogs, such as cholesteryl hemisuccinate (CHS), can stabilize some mammalian receptors for structural studies (Hanson et al., 2008; Jaakola et al., 2008; Shimamura et al., 2011; Xu et al., 2011). To evaluate the effect of CHS on the stability of hZnT1 $\triangle \mathrm{C}$, DDM and LMNG solutions were supplemented with $0.2 \%(\mathrm{w} / \mathrm{v})$ CHS. Our results, on the basis of GFP fluorescence levels, indicate that the addition of CHS improved detergent extraction efficiency. We also noted a slightly higher melting temperature $\left(T_{m}\right)$ for $\mathrm{hZnT} 1 \Delta \mathrm{C}$ in DDM-solubilized membranes supplemented with $\mathrm{CHS}\left(\sim 3^{\circ} \mathrm{C}\right)$ relative to DDM (in the absence of CHS) or LMNG (in the absence or presence of CHS) solubilized membranes. Whereas, no significant difference in $T_{m}$ were observed for hZnT1 in DDM and LMNG solutions supplemented with CHS (Figure 2).

We also investigated the effect of different lipids on the thermostability of hZnT1 $\Delta \mathrm{C}$ using GFP fluorescence (GFP-TS). We heated hZnT1 $\Delta \mathrm{C}$ to $5^{\circ} \mathrm{C}$ above its apparent $T_{m}\left(\sim 37^{\circ} \mathrm{C}\right)$ and compared the protein thermostability after supplementation with different lipids. As observed in Figure 2D, lipids such as DOPC, DOPE, sphingomyelin, bovine lipids and E. coli lipids had little or no effect on the thermostability of $\operatorname{hZnT1} \Delta \mathrm{C}$, whereas DOPG, cholesterol and brain lipids improved the thermostability of the protein, where the measured fluorescence increased by 17,47 , and $30 \%$, respectively. An interesting result was observed for monoolein, the typical host lipid for lipid cubic phase crystallography (LCP). Monoolein reduced the stability of the protein when compared to the non-heated control. However, addition of cholesterol or brain lipids (1:1) reversed this destabilizing effect of monoolein.

Taken together, the results indicate that the cholesterol analog CHS has a stabilizing effect on detergent solubilized hZnT1 $\Delta \mathrm{C}$, and as such, was incorporated into subsequent protocols for purification and crystallization trials.

\section{Purified hZnT1 $\Delta \mathrm{C}$ Can Transport $\mathrm{Zn}^{2+}$ in Reconstituted Liposomes}

$\mathrm{ZnT1}$ has been described as a multifunctional protein, whose activities involve cell protection from zinc toxicity (Palmiter, 2004), inhibition of the L type calcium channels (LTCC) (Beharier et al., 2007; Shusterman et al., 2017), and activation of Ras-Raf-ERK signaling pathway (Bruinsma et al., 2002; Jirakulaporn and Muslin, 2004). More recently, Shusterman and co-workers demonstrated that ZnT1 from mammalian cells acts as a $\mathrm{Zn}^{2+} / \mathrm{H}^{+}$exchanger protecting cells against zinc toxicity. This feature has been observed for zinc transporters (Chao and Fu, 2004; Ohana et al., 2009; Golan et al., 2019) and other members of the CDF family (Guffanti et al., 2002; Xu et al., 2019). Under this mechanism, the protein uses a proton drive force to transport divalent metals ions from the cytoplasm either to the outside of cells or into subcellular compartments (Chao and $\mathrm{Fu}$, 2004).

To evaluate the antiporter mechanism of recombinant hZnT1, we reconstituted hZnT1 $\Delta \mathrm{C}$ and E. coli $\mathrm{F}_{0} \mathrm{~F}_{1}$ ATP synthase into liposomes containing L- $\alpha$-phosphatidylcholine and brain lipids (1:1 lipids ratio). In this experimental setup, ATP synthase acidifies the lumen of the liposomes by ATP-driven proton 


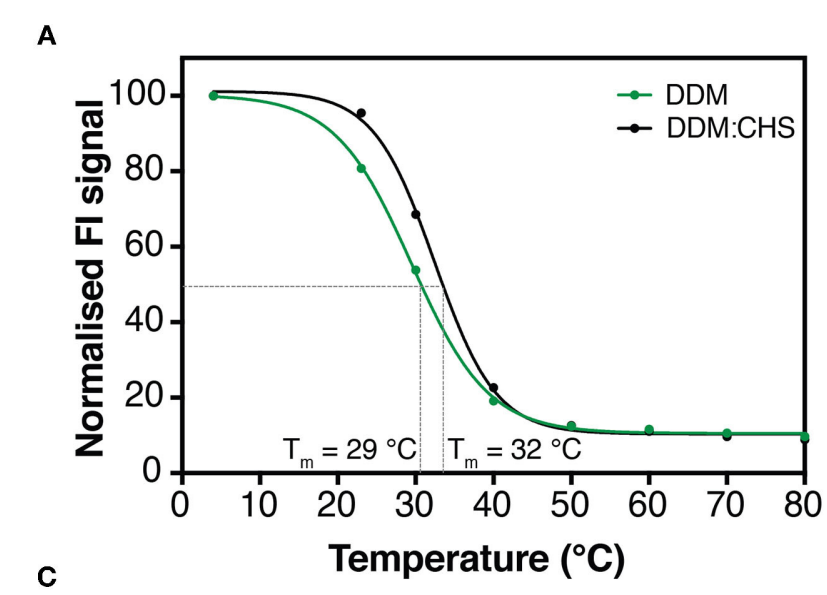

B

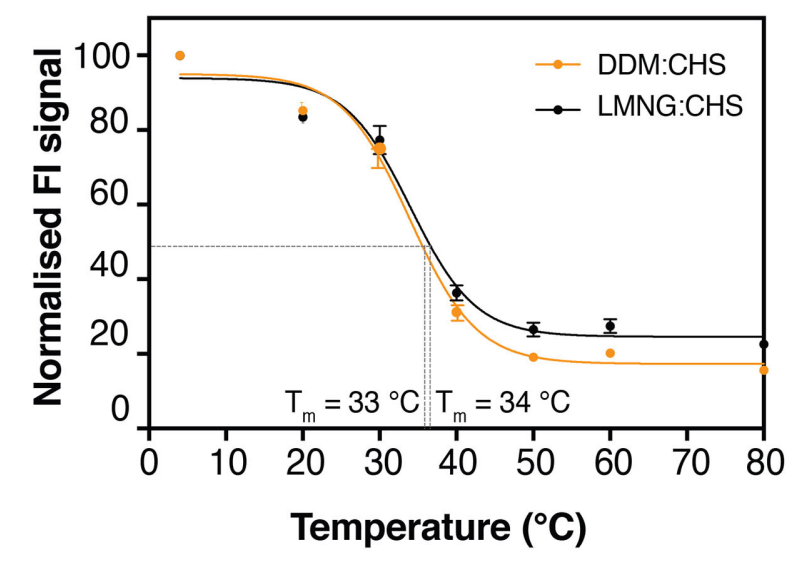

D
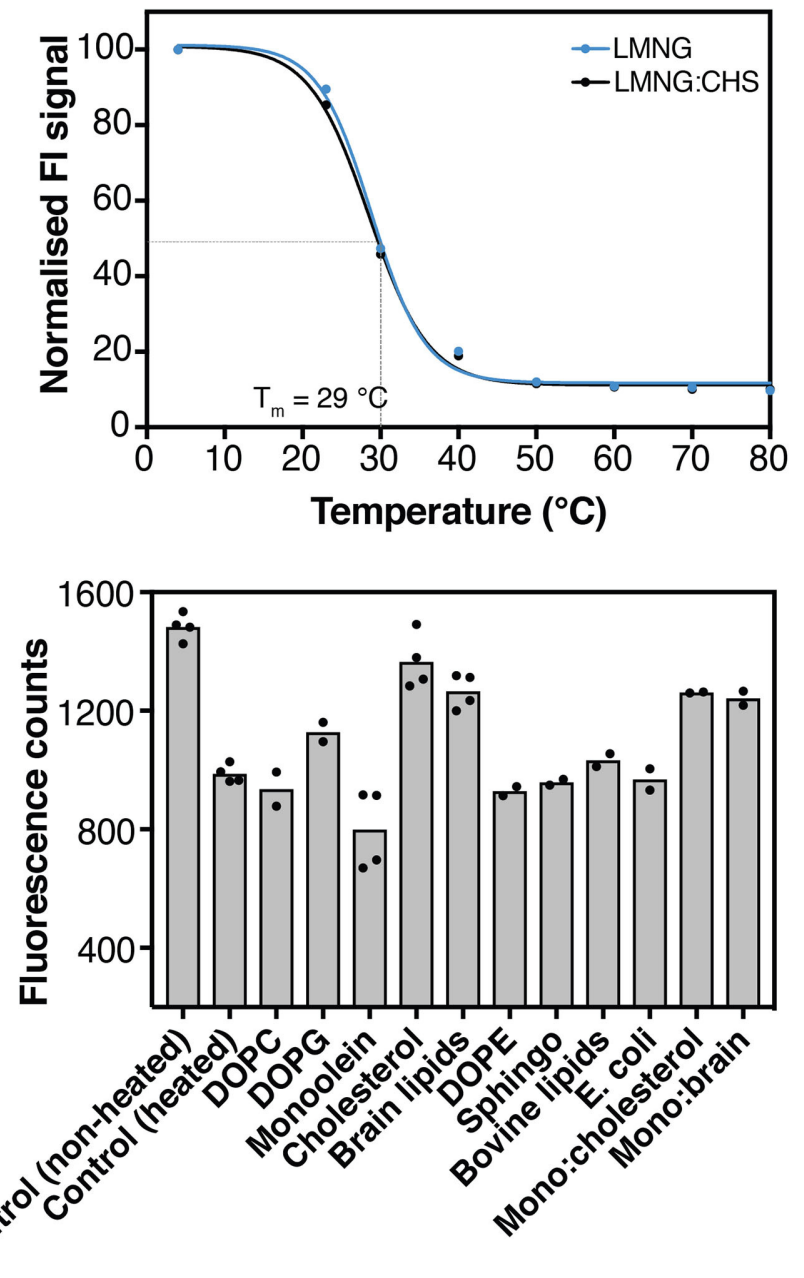

FIGURE 2 | GFP-based thermal shift assay for $h Z n T 1 \Delta C$ and hZnT1. (A) GFP-thermostability (GFP-TS) melting curves for crude-DDM solubilized hZnT1 $\Delta C$ in the absence (green) and presence of CHS (black). (B) GFP-TS melting curves for crude-LMNG solubilized hZnT1 $\triangle \mathrm{C}$ in the absence (cyan) and presence of CHS (black). (C) GFP-TS melting curves for crude-DDM:CHS (orange) and LMNG:CHS (black) solubilized hZnT1. Curves were fitted to a sigmoidal dose-response curve as described in material and methods. (D) Effect of different lipids on the fluorescence counts of purified $\mathrm{hZnT1} \triangle \mathrm{C}$ before and after heat treatment; individual data points indicate technical replicates.

pumping, which is monitored by a decrease in the fluorescence of the signal molecule ACMA (Figure 3A). In hZnT1 $\triangle \mathrm{C}$ containing proteoliposomes, the addition of $\mathrm{Zn}^{2+}$ ions will induce dequenching of ACMA fluorescence due to antiporter activity. To avoid the build-up of a membrane potential $(\Delta \psi)$, valinomycin and potassium are retained throughout the experiment, so that transport is primarily driven by the outwardly directed $\mathrm{pH}$ gradient. As shown in Figure 3B, an increase in fluorescence (ACMA dequenching) after addition of $\mathrm{Zn}^{2+}$ was detected for liposomes containing hZnT1 $\Delta \mathrm{C}$. However, an increase in the signal was also observed for the control (ATP synthase with no hZnT1 $\Delta \mathrm{C}$ added). This behavior is likely due to the interaction of $\mathrm{Zn}^{2+}$ with the liposomes, since addition of $\mathrm{Na}^{+}$ (control) does not change the ACMA signal. Divalent cations can induce liposome fusion leading to leakage (Ellens et al., 1985), which may explain the increase in ACMA fluorescence.
Indeed, Merriman and co-workers reported vesicle leakage after reconstitution of human ZnT8 in liposomes containing E. coli polar lipid extract (Merriman et al., 2016). Nevertheless, the induced response of the proteoliposomes containing hZnT1 $\Delta \mathrm{C}$ is measurably higher than the ATP synthase-only control, indicating that the recombinant $\mathrm{hZnT} 1 \Delta \mathrm{C}$ is functional. To determine an apparent $K_{m}$ for $\mathrm{Zn}^{2+}$, the amount of ACMA dequenching over a range of various concentration of zinc was used and an apparent $K_{m}$ of $1.42 \mathrm{mM}$ was calculated (Figure 3C), similar to values observed for SoYiiP (Lopez-Redondo et al., 2020).

We also investigated the effect of $\mathrm{Ca}^{2+}$ and $\mathrm{Mn}^{2+}$ on the hZnT1 antiporter activity. Several studies have shown that some members of the CDF family recognize and transport other metals such as $\mathrm{Cd}^{2+}$ (Chao and Fu, 2004; Wei and Fu, 2005; Podar et al., 2012). In this assay, we found that $h Z n T 1 \Delta C$ discriminates 


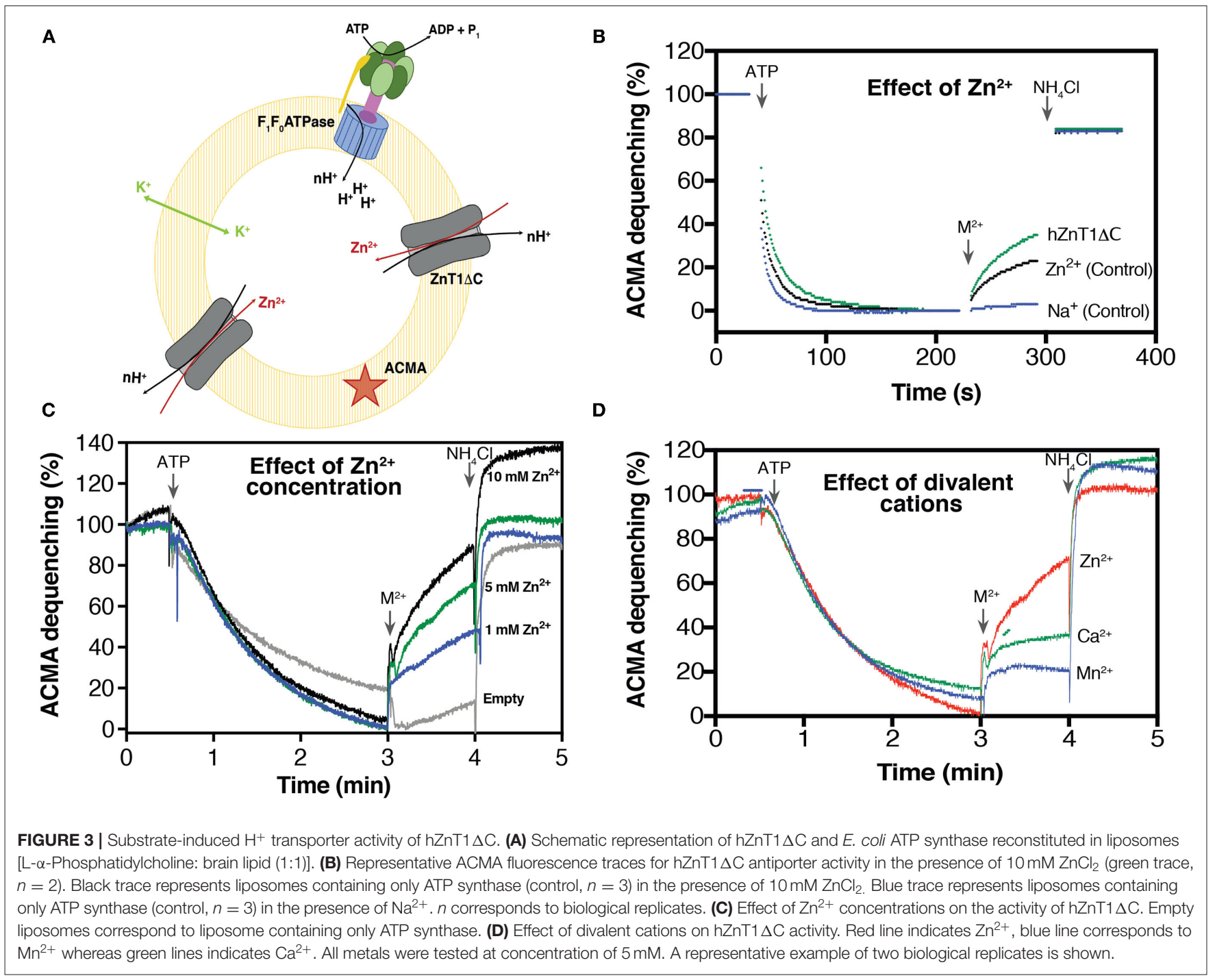

against $\mathrm{Ca}^{2+}$ and $\mathrm{Mn}^{2+}$ (Figure 3D), as low transport rates were observed in the presence of these two metals. This result agrees with reports of mammalian ZnT5 and ZnT8 activity (Hoch et al., 2012), suggesting that $\mathrm{ZnT}$ proteins have a high selectivity for $\mathrm{Zn}^{2+}$.

\section{hZnT1-CTD Can Be Produced in E. coli Cells}

For expression of the C-terminal soluble domain (CTD) of hZnT1, the coding sequence for residues 342-507 was cloned into a pET vector encoding a C-terminal His-tag. As the gene sequence we used was originally optimized for yeast expression, and after rare codons analysis [Graphical Codon Usage Analyser (Fuhrmann et al., 2004)], we chose to express hZnT1-CTD in Rosetta-gami (DE3) cells containing the pRARE vector, which encodes tRNA genes for rare codons (Novy et al., 2001). After expression trials, we found the optimal conditions to be the use of auto-induction media at $30^{\circ} \mathrm{C}$ for $22 \mathrm{~h}$.
Purification of hZnT1-CTD involved a multi buffer system using immobilized metal affinity chromatography (IMAC), SEC and anion exchange chromatography (MonoQ) (see Materials and Methods). As initial purification attempts in the presence of MES pH 6 buffer led to unstable protein at concentrations $>$ than $5 \mathrm{mg} / \mathrm{mL}$, thermo-shift assay was used to assess protein stability and to improve purification yield (see below).

\section{hZnT1-CTD Stability Increases at Low pH}

To rapidly assess hZnT1-CTD stability in different conditions, we carried out a protein thermal shift assay using the Protein Thermal Shift ${ }^{\mathrm{TM}}$ Dye Kit. In this assay, the Protein Thermal Shift dye binds to hydrophobic regions of proteins as they become solvent-exposed due to denaturation to give a fluorescent adduct.

We observed during hZnT1-CTD purification that the protein tends to aggregate in MES buffer $\mathrm{pH}$ 6.0, at concentrations $>5 \mathrm{mg} / \mathrm{mL}$. A low concentration of purified hZnT1-CTD (1 $\mathrm{mg} / \mathrm{mL}$ ) was incubated with buffers ranging from $\mathrm{pH} 3.0$ to 10.0 (Supplementary Table 2). The results indicate that hZnT1-CTD 
is more stable at low $\mathrm{pH}$, such as in buffers glycine- $\mathrm{HCl} \mathrm{pH}$ 3.6 or sodium acetate $\mathrm{pH} 4.5$ and 5.0 (Figure $4 \mathrm{C}$ ). We chose to use sodium acetate $\mathrm{pH} 4.5$ buffer for further evaluation of hZnT1-CTD stability.

hZnT1-CTD gave a typical sigmoidal profile, with an initial low fluorescence signal that transitions to a higher plateau as a temperature gradient induces the protein to unfold and expose its hydrophobic residues to the dye (Figure 4A). These measurements allow an apparent "melting" temperature $\left(T_{m}\right.$, a relative measure of protein stability) to be determined from the derivative of the profile (Figure 4B).

In MES buffer hZnT1-CTD exhibited an apparent $\mathrm{T}_{\mathrm{m}}$ of $55^{\circ} \mathrm{C}$. The apparent $T_{m}$ of hZnT1-CTD increased significantly to $71^{\circ} \mathrm{C}$ in the presence of sodium acetate buffer pH 4.5 (Figure 4B). We also investigated the effect of divalent cations and additives on hZnT1-CTD stability. The results indicate that $\mathrm{Zn}^{2+}$, but not other divalent metals, slightly increases the apparent $T_{m}$ from 55 to $58^{\circ} \mathrm{C}$ (Figure 4D). This result is not surprising, since previous studies have demonstrated that CTDs from zinc transporter orthologs bind $\mathrm{Zn}^{2+}$ ions (Cherezov et al., 2008). However, we expected a greater stabilization effect, since $\mathrm{Zn}^{2+}$ increased the apparent $T_{m}$ of hZnT8 CTD by $\sim 10^{\circ} \mathrm{C}$ (Parsons et al., 2018). The smaller increase in apparent $T_{m}$ for hZnT1CTD may be due to the presence of $\mathrm{Zn}^{2+}$ ions in the expression media (auto-induction media is supplemented with $\mathrm{Zn}^{2+}$ ). If the $\mathrm{Zn}^{2+}$ ions are carried through the purification steps they may occupy the stabilizing binding sites, as observed for SoYiiP (Lopez-Redondo et al., 2018). We note that the zinc binding site of the SoYiiP CTD has been described as the one with the highest affinity for zinc ( $\mathrm{Lu}$ and Fu, 2007; Lu et al., 2009; Coudray et al., 2013).

Taken together, these results suggest that a low $\mathrm{pH}$ buffer and the presence of $\mathrm{Zn}^{2+}$ increase the stability of hZnT1-CTD. Therefore, the original purification protocol was modified to include a buffer exchange step, from Tris $\mathrm{pH} 7.5$ into sodium acetate $\mathrm{pH} 4.5$ buffer. This protocol led to a reproducibly stable protein solution with purity levels $>95 \%$, which could be concentrated up to $12 \mathrm{mg} / \mathrm{mL}$ (Supplementary Figure 4).

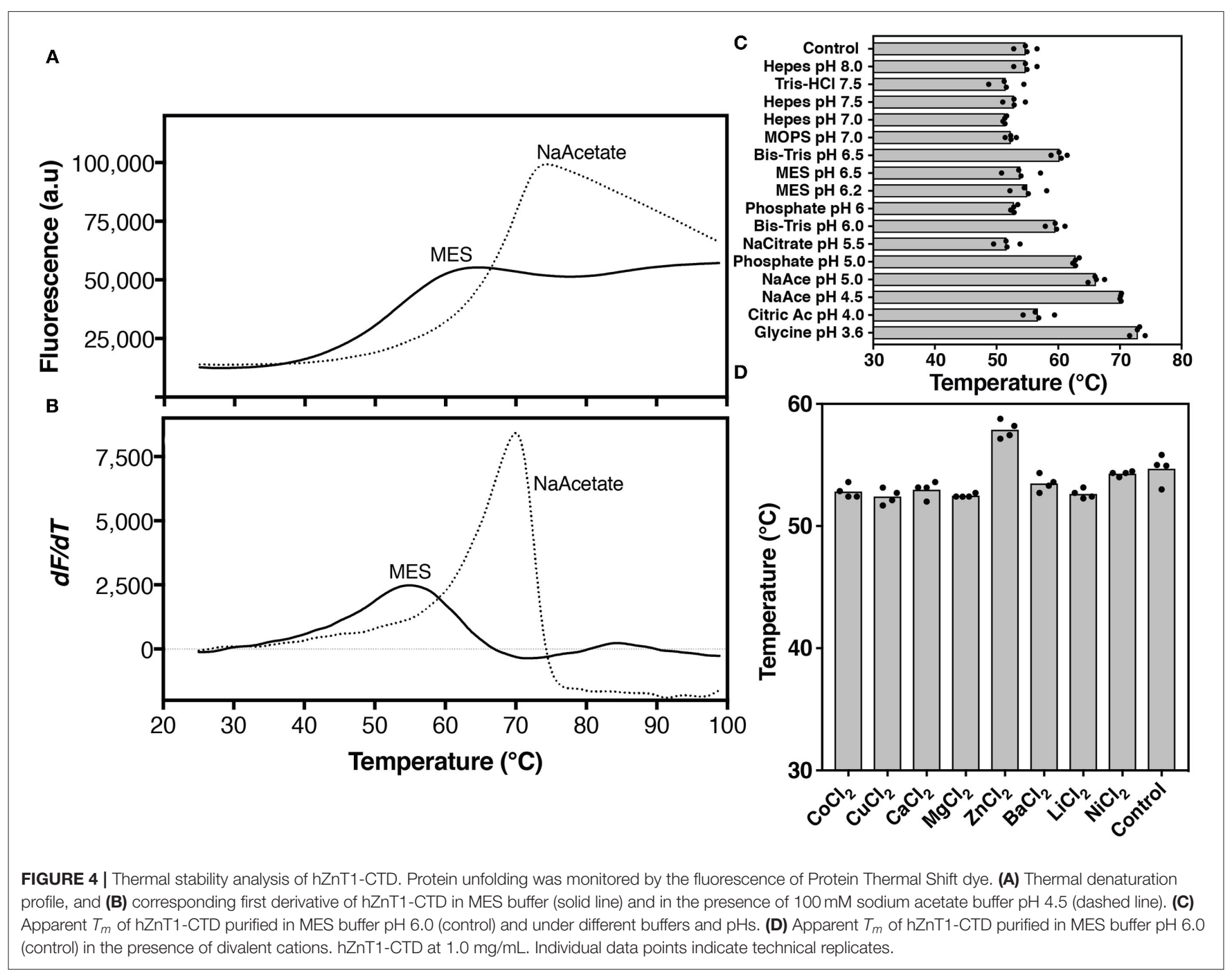




\section{Crystallization of hZnT1 Variants}

The generation of good quality crystals is often a ratedetermining step in the determination of macromolecular structure of membrane proteins by X-ray crystallography (Suzuki et al., 2010; Batyuk et al., 2016). Several approaches have been implemented to increase crystallization success, including point mutations, truncations, addition of signal peptides and/or monoclonal antibodies, and insertion of water-soluble fusion proteins (Birch et al., 2018). We have shown that hZnT1 $\Delta \mathrm{C}$ is functional when fused with GFP, and we hypothesized that the presence of the GFP tag might assist hZnT1 crystallization, as has been shown for crystallization of some other small proteins (Suzuki et al., 2010).

Initial crystallization screens revealed crystals for both hZnT1 and hZnT1 $\Delta \mathrm{C}$ in several conditions (Supplementary Figure 5). Many of the hit conditions included divalent metals, mainly $\mathrm{Ca}^{2+}$ and $\mathrm{Mg}^{2+}$ but very few had $\mathrm{Zn}^{2+}$ present. This is possibly because zinc was carried through from expression through purification, and was already bound to the protein. Trials involving lipid cubic phase (LCP) crystallization were also performed and although we were able to identify a condition containing crystals, these disappeared over time and could not be reproduced (Supplementary Figure 6).

Further optimization of the crystals was carried out by varying protein and precipitant concentrations, $\mathrm{pH}$, presence and absence of $\mathrm{Zn}^{2+}$, drop size and ratio, detergent type and by decreasing the temperature from 22 to $8^{\circ} \mathrm{C}$. We found that several crystallization conditions were reproducible, but we could not obtain crystals larger than $50 \mu \mathrm{m}$, or measure diffraction beyond a resolution of $13 \AA$ (Supplementary Figure 7).

The likely reasons for small crystals and poor diffraction are low purity and high conformational heterogeneity. A high level of purity is not essential for initial crystallization screening: it has been shown that $75 \%$ purity can be tolerated to obtain crystals using the vapor-diffusion technique (Kors et al., 2009). However, in that work, crystals obtained under those purity levels did not diffract beyond $10 \AA$ (Kors et al., 2009). Although the fusion protein we crystallized was also found to be active, we estimate that the purity was below $80 \%$ for both hZnT1 and hZnT1 $\Delta \mathrm{C}$ and this could contribute to small crystal size and poor diffraction.

A high degree of conformational heterogeneity can inhibit crystallization or limit diffraction resolution. Our construct includes a 10-residue linker between the target and GFP fusion protein that could lead to conformational heterogeneity that inhibits crystal contact formation (Suzuki et al., 2010). Linkers of $<5$ residues have been used to crystallize soluble proteins fused to MBP or GFP (Center et al., 1998; Suzuki et al., 2010). We propose that a shorter linker and higher purity could yield larger and higher quality ZnT1 crystals.

We also attempted to crystallize hZnT1-CTD using the hanging drop vapor diffusion technique. However, no crystals were observed using this construct.

\section{hZnT1-CTD Forms Dimers With a V-Shaped Core}

The CTD has been reported to play an important role in the mechanism of action of $\mathrm{ZnT}$ and other proteins belonging to the CDF family; however, its conformational changes upon $\mathrm{Zn}^{2+}$ binding are still unclear. Whilst some studies classify the CTD as a metal sensor that undergoes conformational changes upon zinc binding leading to changes on the transmembrane helices (TMH) (Lu et al., 2009), others suggest that the affinity between CTD and zinc is very high, such that zinc is always bound and conformational changes occur only in the TMD (Lopez-Redondo et al., 2018). The recently reported hZnT8 structure supports the latter contention as $\mathrm{Zn}^{2+}$ ions were bound to the CTD even though the samples were prepared in the absence of $\mathrm{Zn}^{2+}$. Furthermore, comparisons of the inward- and outward-facing conformations of ZnT8 strongly suggest that the CTD remains static during the transport cycle (Xue et al., 2020).

The hZnT8 structure confirms that its CTD is dimeric (Xue et al., 2020), as previously reported by Parsons and co-workers (Parsons et al., 2018), and as observed for bacterial CTD (Cherezov et al., 2008; Higuchi et al., 2009; Uebe et al., 2011; Zeytuni et al., 2014). However, a recent study showed that hZnT8CTD can form a tetramer in solution (Ullah et al., 2020).

We used small-angle X-ray scattering (Supplementary Table 3) to determine the oligomeric state and low-resolution solution structure of hZnT1-CTD (Figure 5). The estimated mass of the protein from the SAXS data is 41 $\mathrm{kDa}$, indicating that the protein is present in solution as a dimer. Dummy atom modeling of the scattering data yields an elongated structure (Figure 5C, magenta envelope) whereas the rigid-body modeling against the scattering data yields a structure with a $\mathrm{V}$-shaped core (Figure 5C, black ribbon representation), consistent with homologous proteins from prokaryotic organism. The homology structure was generated from the primary sequence using iTasser (Yang et al., 2014), and while good structure templates exist for residues 342-422, there are no structural templates for residues 422-507. As such, these residues were predicted by iTasser to be primarily coil (in a globular arrangement). Analysis of the sequence and small-angle scattering do not yield a consistent picture of the nature of this region of the protein. Sequence analysis shows that hZnT1-CTD has a longer tail than other homologs (Supplementary Figure 8) that is predicted to be disordered (Supplementary Figure 2). Rigid-body models optimized against the scattering data using the globular coil region as a "placeholder" yielded an excellent fit to the scattering data. While the predicted atomic structure of this region is unlikely to be representative of its actual structure, at low-resolution, the scattering data appears to be consistent with the notion that residues $422-507$ are capable of forming a globular domain.

Previous studies suggest that the CTD of some CDF members adopts a more rigid and compact structure upon $\mathrm{Zn}^{2+}$ binding (Cherezov et al., 2008; Higuchi et al., 2009; Zeytuni et al., 2014; Ullah et al., 2020). However, the hZnT8-CTD structure shows no conformational differences between apo and $\mathrm{Zn}$-bound CTD forms (Xue et al., 2020). This recent observation raises the question whether variations within the CTD caused by bound $\mathrm{Zn}^{2+}$ is species-dependent. Structural comparisons of our CTD model (large globular domain) with hZnT8-CTD gave an RMSD of $8 \AA$ for $147 \mathrm{C} \alpha$ atoms, with the main difference observed in helix-1, which led to a more compact structure 

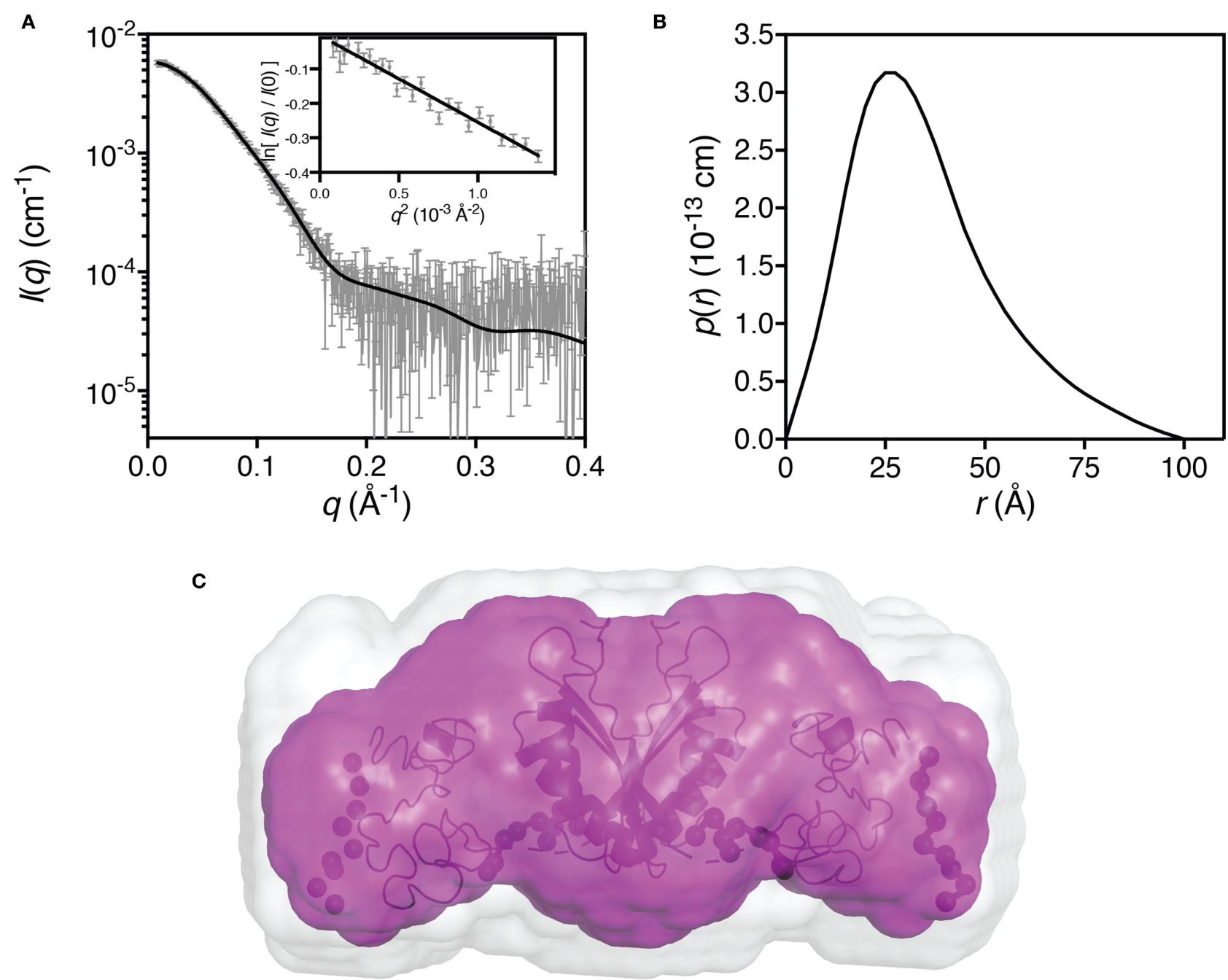

FIGURE 5 | Small-angle X-ray scattering data for hZnT1-CTD. (A) Measured scattering data for hZnT1-CTD (gray). The scattering profile of the rigid-body model is shown as solid black lines overlaid on the scattering data ( $\chi^{2}=1.27$; CorMap test (Franke et al., 2015), 475 points, $\left.C=12, P=0.108\right)$. Insert: Guinier plot for $q R_{g}<$ $1.0\left(R^{2}=0.94\right)$; (B) The pair-distance distribution function, $p(r)$, derived from the scattering data are indicative of an elongated structure with a maximum dimension of $\sim 100 \AA$; (C) Probable shape of the hZnT1-CTD dimer obtained from the filtered average of 16 dummy-atom models (magenta envelope): $\chi^{2}=1.252 \pm 0.002 ;$ NSD $=0.553 \pm 0.026$; Resolution $=26 \pm 2 \AA$. Image in C was generated using PyMol (The PyMOL Molecular Graphics System, Schrödinger, LLC), where the light gray shape represents the total volume encompassed by the aligned dummy-atom models. The rigid-body model is shown as a black ribbon diagram aligned to the filtered model (flexible regions are represented by chains of black spheres).

in our model (Supplementary Figure 9). Whilst the RMSD is high, the overall model of hZnT1-CTD is in agreement with the hZnT8-CTD structure.

The hZnT8-CTD structure has two $\mathrm{Zn}^{2+}$ binding sites per monomer. However, the location and chemical environment of these are distinct from those in EcYiiP and SoYiiP. Whereas, $\mathrm{Zn}^{2+}$ ions have water molecules participating in the ion coordination in the YiiP structures, the hZnT8 map showed that the $\mathrm{Zn}^{2+}$ ions are in a classical tetrahedral geometry, with $\mathrm{Zn}^{2+}$ chelated by the HCH (His52-Cys53-His54) motif. This motif plays a role in $\mathrm{Zn}^{2+}$ transport, as its deletion leads to reduced $\mathrm{Zn}^{2+}$ transport rates (Xue et al., 2020). Although the HCH motif is conserved in $\mathrm{ZnT}$ (homologs, it is not conserved in $\mathrm{ZnT} 1$ nor across the ZnT family; in fact, only ZnT2 and ZnT3 contain the motif. This raises questions about differences in the $\mathrm{Zn}^{2+}$ binding sites, the existence of other motifs that might be crucial for $\mathrm{Zn}^{2+}$ transport within the ZnT family, and whether the lack of the $\mathrm{HCH}$ motif would affect the two-state model of $\mathrm{Zn}^{2+}$ transport proposed (Xue et al., 2020).

Several studies have attempted to elucidate the structurefunction relationship of the CTD of CDF members (Cherezov et al., 2008; Higuchi et al., 2009; Uebe et al., 2011; Zeytuni et al., 2014; Parsons et al., 2018; Ullah et al., 2020), showing that despite the high sequence divergence, all available CTD structures share a similar metallochaperone-like fold. However, the role of this domain in the transport mechanism of CDF members is still 
unclear. Xue and co-workers suggested from their structural studies of hZnT8 that the CTD along with TM3 and TM6 remain static between outward- and inward-facing states. Moreover, they pointed out that the CTD indirectly influences $\mathrm{Zn}^{2+}$ transport due to its interactions with the $\mathrm{HCH}$ motif, which restrict rearrangements in TMH1 leading to a wide cytosolic cavity in the inward conformation favoring $\mathrm{Zn}^{2+}$ binding (Xue et al., 2020). This knowledge contributes immensely to the field, though does not preclude distinct conformational changes occurring in other ZnTs and CDF members that lack the HCH motif, such as ZnT1.

\section{CONCLUSIONS}

In the present study, we developed methods to reproducibly express and purify full-length human $\mathrm{ZnT1}$, a C-terminal truncated variant $(\mathrm{hZnT} 1 \Delta \mathrm{C})$, and its soluble CTD. Functional assays indicate that $\mathrm{hZnT} 1 \Delta \mathrm{C}$ has $\mathrm{Zn}^{2+} / \mathrm{H}^{+}$antiporter activity. Crystallization of hZnT1 and hZnT1 $\Delta \mathrm{C}$ yielded crystals in several conditions; however, diffraction beyond $13 \AA$ could not be achieved, suggesting that higher purity or a shorter linker may be required. Biochemical characterization of ZnT1-CTD indicates that this recombinant protein is stable at low $\mathrm{pH}(\sim 4.5)$ and SAXS data support the formation of a dimer in solution that has a V-shaped core, similar to many other CTDs. These findings provide a basis for future structure-function studies of ZnT1 with potential for application to other ZnTs and CDFs. Followon experiments to increase our understanding of this class of proteins could include assessing: (i) the apparent $\mathrm{Km}$ of hZnT1 in comparison to $\mathrm{hZnT} 1 \Delta \mathrm{C}$ in liposome assays; (ii) the orientation of the protein after reconstitution in liposomes; (iii) the effect of different micelle sizes for hZnT1 and hZnT1 $\Delta \mathrm{C}$ as an alternative to investigate the role of the CTD in protein oligomerization and; iv) whether the combination of CHS and brain lipids can further increase protein stability.

\section{REFERENCES}

Andrews, G. K., Wang, H., Dey, S. K., and Palmiter, R. D. (2004). Mouse zinc transporter 1 gene provides an essential function during early embryonic development. Genesis 40, 74-81. doi: 10.1002/gene.20067

Batyuk, A., Wu, Y., Honegger, A., Heberling, M. M., and Plückthun, A. (2016). DARPin-based crystallization chaperones exploit molecular geometry as a screening dimension in protein crystallography. J. Mol. Biol. 428, 1574-1588. doi: 10.1016/j.jmb.2016.03.002

Beharier, O., Dror, S., Levy, S., Kahn, J., Mor, M., Etzion, S., et al. (2012). ZnT-1 protects HL-1 cells from simulated ischemia-reperfusion through activation of Ras-ERK signaling. J. Mol. Med. 90, 127-138. doi: 10.1007/s00109-011-0845-0

Beharier, O., Etzion, Y., Katz, A., Friedman, H., Tenbosh, N., Zacharish, S., et al. (2007). Crosstalk between L-type calcium channels and ZnT-1, a new player in rate-dependent cardiac electrical remodeling. Cell Calcium 42, 71-82. doi: 10.1016/j.ceca.2006.11.007

Birch, J., Axford, D., Foadi, J., Meyer, A., Eckhardt, A., Thielmann, Y., et al. (2018). The fine art of integral membrane protein crystallisation. Methods 147, 150-162. doi: 10.1016/j.ymeth.2018.05.014

Blindauer, C. A. (2015). Advances in the molecular understanding of biological zinc transport. Chem. Commun. 51, 4544-4563. doi: 10.1039/C4CC10174J

Bruinsma, J. J., Jirakulaporn, T., Muslin, A. J., and Kornfeld, K. (2002). Zinc ions and cation diffusion facilitator proteins regulate ras-mediated signaling. Dev. Cell 2, 567-578. doi: 10.1016/S1534-5807(02)00151-X

\section{DATA AVAILABILITY STATEMENT}

The datasets presented in this study can be found in online repositories. The names of the repository/repositories and accession number(s) can be found in the article/Supplementary Material.

\section{AUTHOR CONTRIBUTIONS}

$\mathrm{CC}$ and RJ performed research, data analysis, and wrote the first draft. AW performed SAXS studies. HC conducted cloning and solubilization studies. JM and DD project conceptualization, project funding, and data analysis. All authors contributed to the draft of the manuscript and approved the final version.

\section{FUNDING}

The following funding is acknowledged: Australian Research Council (Grant No. DP160101702 to JM and DD).

\section{ACKNOWLEDGMENTS}

We acknowledge the use of the University of Queensland Remote Operation Crystallization and X-ray (UQ ROCX) facility at the Center for Microscopy and Microanalysis and the support from staff, Gordon King and Karl Byriel. Additionally, we thank the Australian Synchrotron MX and SAXS facilities and the beamline staff for their support.

\section{SUPPLEMENTARY MATERIAL}

The Supplementary Material for this article can be found online at: https://www.frontiersin.org/articles/10.3389/fchem. 2021.667803/full\#supplementary-material

Center, R. J., Kobe, B., Wilson, K. A., Teh, T., Kemp, B. E., Poumbourios, P., et al. (1998). Crystallization of a trimeric human T cell leukemia virus type 1 gp21 ectodomain fragment as a chimera with maltose-binding protein. Protein Sci. 7, 1612-1619. doi: 10.1002/pro.5560070715

Chao, Y., and Fu, D. (2004). Kinetic study of the antiport mechanism of an Escherichia coli zinc transporter, ZitB. J. Biol. Chem. 279, 12043-12050. doi: 10.1074/jbc.M313510200

Cherezov, V., Höfer, N., Szebenyi, D. M. E., Kolaj, O., Wall, J. G., Gillilan, R., et al. (2008). Insights into the mode of action of a putative zinc transporter CzrB in Thermus thermophilus. Structure 16, 1378-1388. doi: 10.1016/j.str.2008.05.014

Chowanadisai, W., Lönnerdal, B., and Kelleher, S. L. (2006). Identification of a mutation in SLC30A2 (ZnT-2) in women with low milk zinc concentration that results in transient neonatal zinc deficiency. J. Biol. Chem. 281, 39699-39707. doi: 10.1074/jbc.M605821200

Cotrim, C. A., Jarrott, R. J., Martin, J. L., and Drew, D. (2019). A structural overview of the zinc transporters in the cation diffusion facilitator family. Acta Crystallogr. Sect. D Struct. Biol. 75, 357-367. doi: 10.1107/S2059798319003814

Coudray, N., Valvo, S., Hu, M., Lasala, R., Kim, C., Vink, M., et al. (2013). Inward-facing conformation of the zinc transporter YiiP revealed by cryoelectron microscopy. Proc. Natl. Acad. Sci. U. S. A. 110, 2140-2145. doi: $10.1073 /$ pnas. 1215455110

Deller, M. C., Kong, L., and Rupp, B. (2016). Protein stability: a crystallographer's perspective. Acta Crystallogr. Sect. Struct. Biol. Commun. 72, 72-95. doi: 10.1107/S2053230X15024619 
Drew, D., Newstead, S., Sonoda, Y., Kim, H., von Heijne, G., and Iwata, S. (2008). GFP-based optimization scheme for the overexpression and purification of eukaryotic membrane proteins in Saccharomyces cerevisiae. Nat. Protoc. 3, 784-798. doi: 10.1038/nprot.2008.44

Ellens, H., Bentz, J., and Szoka, F. C. (1985). Proton- and calciuminduced fusion and destabilization of liposomes. Biochemistry 24, 3099-3106. doi: 10.1021/bi00334a005

Fischer, H., De Oliveira Neto, M., Napolitano, H. B., Polikarpov, I., and Craievich, A. F. (2010). Determination of the molecular weight of proteins in solution from a single small-angle X-ray scattering measurement on a relative scale. J. Appl. Crystallogr. 43, 101-109. doi: 10.1107/S0021889809043076

Franke, D., Jeffries, C. M., and Svergun, D. I. (2015). Correlation Map, a goodnessof-fit test for one-dimensional X-ray scattering spectra. Nat. Methods 12, 419-422. doi: 10.1038/nmeth.3358

Fuhrmann, M., Hausherr, A., Ferbitz, L., Schödl, T., Heitzer, M., and Hegemann, P. (2004). Monitoring dynamic expression of nuclear genes in Chlamydomonas reinhardtii by using a synthetic luciferase reporter gene. Plant Mol. Biol. 55, 869-881. doi: 10.1007/s11103-005-2150-1

Fukue, K., Itsumura, N., Tsuji, N., Nishino, K., Nagao, M., Narita, H., et al. (2018). Evaluation of the roles of the cytosolic N-terminus and His-rich loop of ZNT proteins using ZNT2 and ZNT3 chimeric mutants. Sci. Rep. 8:14084. doi: 10.1038/s41598-018-32372-8

Golan, Y., Alhadeff, R., Warshel, A., and Assaraf, Y. G. (2019). ZnT2 is an electroneutral proton-coupled vesicular antiporter displaying an apparent stoichiometry of two protons per zinc ion. PLoS Comput. Biol. 15:e1006882. doi: 10.1371/journal.pcbi.1006882

Guffanti, A. A., Wei, Y., Rood, S. V., and Krulwich, T. A. (2002). An antiport mechanism for a member of the cation diffusion facilitator family: divalent cations efflux in exchange for $\mathrm{K}+$ and $\mathrm{H}+$. Mol. Microbiol. 45, 145-53. doi: 10.1046/j.1365-2958.2002.02998.x

Hanson, M. A., Cherezov, V., Griffith, M. T., Roth, C. B., Jaakola, V. P., Chien, E. Y. T., et al. (2008). A specific cholesterol binding site is established by the $2.8 \AA$ structure of the human $\beta 2$-adrenergic receptor. Structure 16, 897-905. doi: 10.1016/j.str.2008.05.001

Higuchi, T., Hattori, M., Tanaka, Y., Ishitani, R., and Nureki, O. (2009). Crystal structure of the cytosolic domain of the cation diffusion facilitator family protein. Proteins 76, 768-771. doi: 10.1002/prot.22444

Hoch, E., Lin, W., Chai, J., Hershfinkel, M., Fu, D., and Sekler, I. (2012). Histidine pairing at the metal transport site of mammalian $\mathrm{ZnT}$ transporters controls Zn2+ over Cd2+ selectivity. Proc. Natl. Acad. Sci. U. S. A. 109, 7202-7207. doi: $10.1073 /$ pnas. 1200362109

Huang, L., and Tepaamorndech, S. (2013). The SLC30 family of zinc transportersa review of current understanding of their biological and pathophysiological roles. Mol. Aspects Med. 34, 548-560. doi: 10.1016/j.mam.2012.05.008

Ishida, T., and Kinoshita, K. (2007). PrDOS: prediction of disordered protein regions from amino acid sequence. Nucleic Acids Res. 35, W460-W464. doi: 10.1093/nar/gkm363

Jakkola, V. P., Griffith, M. T., Hanson, M. A., Cherezov, V., Chien, E. Y. T., Lane, J. R., et al. (2008). The 2.6 angstrom crystal structure of a human A2A adenosine receptor bound to an antagonist. Science 322, 1211-1217. doi: $10.1126 /$ science. 1164772

Jidenko, M., Nielsen, R. C., Sørensen, T. L. M., Møller, J. V., Le Maire, M., Nissen, P., et al. (2005). Crystallization of a mammalian membrane protein overexpressed in Saccharomyces cerevisiae. Proc. Natl. Acad. Sci. U. S. A. 102, 11687-11691. doi: 10.1073/pnas.0503986102

Jing, H., Kong, C., Liu, T., Zeng, Y., and Zhang, Z. (2018). Zinc transporter 1 (ZnT 1) is overexpressed in bladder cancer and promotes the proliferation and invasion of bladder cancer BIU 87 cells. Int. J. Clin. Exp. Med. 11, 5323-5331.

Jirakulaporn, T., and Muslin, A. J. (2004). Cation diffusion facilitator proteins modulate Raf-1 activity. J. Biol. Chem. 279, 27807-27815. doi: 10.1074/jbc.M401210200

Kawachi, M., Kobae, Y., Mimura, T., and Maeshima, M. (2008). Deletion of a histidine-rich loop of AtMTP1, a vacuolar $\mathrm{Zn}(2+) / \mathrm{H}(+)$ antiporter of Arabidopsis thaliana, stimulates the transport activity. J. Biol. Chem. 283, 8374-8383. doi: 10.1074/jbc.M707646200

Kawate, T., and Gouaux, E. (2006). Fluorescence-detection size-exclusion chromatography for precrystallization screening of integral membrane proteins. Structure 14, 673-681. doi: 10.1016/j.str.2006.01.013
Kimura, T., and Kambe, T. (2016). The functions of metallothionein and ZIP and ZnT transporters: an overview and perspective. Int. J. Mol. Sci. 17:336. doi: $10.3390 /$ ijms 17030336

Kirby, N., Cowieson, N., Hawley, A. M., Mudie, S. T., McGillivray, D. J., Kusel, M., et al. (2016). Improved radiation dose efficiency in solution SAXS using a sheath flow sample environment. Acta Crystallogr. Sect. D Struct. Biol. 72, 1254-1266. doi: $10.1107 /$ S2059798316017174

Kirby, N. M., Mudie, S. T., Hawley, A. M., Cookson, D. J., Mertens, H. D. T., Cowieson, N., et al. (2013). A low-background-intensity focusing smallangle X-ray scattering undulator beamline. J. Appl. Crystallogr. 46, 1670-1680. doi: 10.1107/S002188981302774X

Kolaj-Robin, O., Russell, D., Hayes, K. A., Pembroke, J. T., and Soulimane, T. (2015). Cation diffusion facilitator family: structure and function. FEBS Lett. 589, 1283-1295. doi: 10.1016/j.febslet.2015.04.007

Konarev, P. V., Volkov, V. V., Sokolova, A. V., Koch, M. H. J., and Svergun, D. I. (2003). PRIMUS: a windows PC-based system for small-angle scattering data analysis. J. Appl. Crystallogr. 36, 1277-1282. doi: 10.1107/S0021889803012779

Kors, C. A., Wallace, E., Davies, D. R., Li, L., Laible, P. D., and Nollert, P. (2009). Effects of impurities on membrane-protein crystallization in different systems. Acta Crystallogr. Sect. D Biol. Crystallogr. 65, 1062-1073. doi: 10.1107/S0907444909029163

Kota, J., Gilstring, C. F., and Ljungdahl, P. O. (2007). Membrane chaperone Shr3 assists in folding amino acid permeases preventing precocious ERAD. J. Cell Biol. 176, 617-628. doi: 10.1083/jcb.200612100

Langmade, S. J., Ravindra, R., Daniels, P. J., and Andrews, G. K. (2000). The transcription factor MTF-1 mediates metal regulation of the mouse ZnT1 gene. J. Biol. Chem. 275, 34803-34809. doi: 10.1074/jbc.M007339200

Lehvy, A. I., Horev, G., Golan, Y., Glaser, F., Shammai, Y., and Assaraf, Y. G. (2019). Alterations in ZnT1 expression and function lead to impaired intracellular zinc homeostasis in cancer. Cell Death Discov. 5:144. doi: 10.1038/s41420-019-0224-0

Levy, S., Beharier, O., Etzion, Y., Mor, M., Buzaglo, L., Shaltiel, L., et al. (2009). Molecular basis for zinc transporter 1 action as an endogenous inhibitor of L-type calcium channels. J. Biol. Chem. 284, 32434-32443. doi: 10.1074/jbc.M109.058842

Lopez-Redondo, M., Fan, S., Koide, A., Shohei, K., Beckstein, O., and Stokes, D. L. (2020). Zinc dependent conformational changes in the cation diffusion facilitator YiiP from S. oneidensis. bioRxiv [Preprint]. doi: $10.1101 / 2020.12 .29 .424758$

Lopez-Redondo, M. L., Coudray, N., Zhang, Z., Alexopoulos, J., and Stokes, D. L. (2018). Structural basis for the alternating access mechanism of the cation diffusion facilitator YiiP. Proc. Natl. Acad. Sci. U. S. A. 115, 3042-3047. doi: 10.1073/pnas.1715051115

Lovell, M. A., Smith, J. L., Xiong, S., and Markesbery, W. R. (2005). Alterations in zinc transporter protein-1 (ZnT-1) in the brain of subjects with mild cognitive impairment, early, and late-stage alzheimer's disease. Neurotox. Res. 7, 265-271. doi: 10.1007/BF03033884

Lu, M., Chai, J., and Fu, D. (2009). Structural basis for autoregulation of the zinc transporter YiiP. Nat. Struct. Mol. Biol. 16, 1063-1067. doi: 10.1038/nsmb.1662 Lu, M., and Fu, D. (2007). Structure of the zinc transporter YiiP. Science 317, 1746-1748. doi: 10.1126/science. 1143748

Merriman, C., Huang, Q., Rutter, G. A., and Fu, D. (2016). Lipid-tuned zinc transport activity of human $\mathrm{ZnT} 8$ protein correlates with risk for type-2 diabetes. J. Biol. Chem. 291, 26950-26957. doi: 10.1074/jbc.M116. 764605

Newstead, S., Kim, H., von Heijne, G., Iwata, S., and Drew, D. (2007). Highthroughput fluorescent-based optimization of eukaryotic membrane protein overexpression and purification in Saccharomyces cerevisiae. Proc. Natl. Acad. Sci. U. S. A. 104, 13936-13941. doi: 10.1073/pnas.0704546104

Nji, E., Chatzikyriakidou, Y., Landreh, M., and Drew, D. (2018). An engineered thermal-shift screen reveals specific lipid preferences of eukaryotic and prokaryotic membrane proteins. Nat. Commun. 9:4253. doi: 10.1038/s41467-018-06702-3

Nomura, N., Verdon, G., Kang, H. J., Shimamura, T., Nomura, Y., Sonoda, Y., et al. (2015). Structure and mechanism of the mammalian fructose transporter GLUT5. Nature 526, 397-401. doi: 10.1038/nature14909

Novy, R., Drott, D., Yaeger, K., and Mierendorf, R. (2001). Overcoming the codon bias of E. coli for enhanced protein expression. Newsl. Novagen, INC • Adv. 
Prod. Protoc. Mol. Biol. Res. 12, 1-3. Available online at: http://wolfson.huji.ac. il/expression/rosetta.pdf (accessed May 11, 2015).

Ohana, E., Hoch, E., Keasar, C., Kambe, T., Yifrach, O., Hershfinkel, M., et al. (2009). Identification of the $\mathrm{Zn}{ }^{2+}$ binding site and mode of operation of a mammalian $\mathrm{Zn}{ }^{2+}$ transporter. J. Biol. Chem. 284, 17677-17686. doi: $10.1074 /$ jbc.M109.007203

Palmiter, R. D. (2004). Protection against zinc toxicity by metallothionein and zinc transporter 1. Proc. Natl. Acad. Sci. U. S. A. 101, 4918-4923. doi: $10.1073 /$ pnas.0401022101

Palmiter, R. D., and Findley, S. D. (1995). Cloning and functional characterization of a mammalian zinc transporter that confers resistance to zinc. EMBO J. 14, 639-49. doi: 10.1002/j.1460-2075.1995.tb07042.x

Parsons, D. S., Hogstrand, C., and Maret, W. (2018). The C-terminal cytosolic domain of the human zinc transporter ZnT8 and its diabetes risk variant. FEBS J. 285, 1237-1250. doi: 10.1111/febs.14402

Petoukhov, M. V., Franke, D., Shkumatov, A. V., Tria, G., Kikhney, A. G., Gajda, M., et al. (2012). New developments in the ATSAS program package for small-angle scattering data analysis. J. Appl. Crystallogr. 45, 342-350. doi: $10.1107 /$ S0021889812007662

Podar, D., Scherer, J., Noordally, Z., Herzyk, P., Nies, D., and Sanders, D. (2012). Metal selectivity determinants in a family of transition metal transporters. $J$. Biol. Chem. 287, 3185-3196. doi: 10.1074/jbc.M111.305649

Prasad, A. S. (2013). Discovery of human zinc deficiency: its impact on human health and disease. Adv. Nutr. An Int. Rev. J. 4, 176-190. doi: 10.3945/an.112.003210

Qin, Y., Thomas, D., Fontaine, C. P., and Colvin, R. A. (2009). Silencing of ZnT1 reduces Zn2+ efflux in cultured cortical neurons. Neurosci. Lett. 450, 206-210. doi: 10.1016/j.neulet.2008.11.069

Schütz, M., Schöppe, J., Sedlák, E., Hillenbrand, M., Nagy-Davidescu, G., Ehrenmann, J., et al. (2016). Directed evolution of G protein-coupled receptors in yeast for higher functional production in eukaryotic expression hosts. Sci. Rep. 6:21508. doi: 10.1038/srep21508

Segal, D., Ohana, E., Besser, L., Hershfinkel, M., Moran, A., and Sekler, I. (2004). A role for ZnT-1 in regulating cellular cation influx. Biochem. Biophys. Res. Commun. 323, 1145-1150. doi: 10.1016/j.bbrc.2004.08.211

Shimamura, T., Shiroishi, M., Weyand, S., Tsujimoto, H., Winter, G., Katritch, V., et al. (2011). Structure of the human histamine H 1 receptor complex with doxepin. Nature 475, 65-72. doi: 10.1038/nature10236

Shusterman, E., Beharier, O., Levy, S., Zarivach, R., Etzion, Y., Campbell, C. R., et al. (2017). Zinc transport and the inhibition of the L-type calcium channel are two separable functions of ZnT-1. Metallomics 9, 228-238. doi: 10.1039/C6MT00296J

Shusterman, E., Beharier, O., Shiri, L., Zarivach, R., Etzion, Y., Campbell, C. R., et al. (2014). ZnT-1 extrudes zinc from mammalian cells functioning as a $\mathrm{Zn}(2+) / \mathrm{H}(+)$ exchanger. Metallomics 6, 1656-1663. doi: 10.1039/C4MT00108G

Singh, P. (2017). Budding yeast: an ideal backdrop for in vivo lipid biochemistry. Front. Cell Dev. Biol. 4:156. doi: 10.3389/fcell.2016.00156

Sladek, R., Rocheleau, G., Rung, J., Dina, C., Shen, L., Serre, D., et al. (2007). A genome-wide association study identifies novel risk loci for type 2 diabetes. Nature 445, 881-885. doi: 10.1038/nature05616

Stetsenko, A., and Guskov, A. (2017). An overview of the top ten detergents used for membrane protein crystallization. Crystals 7:1. doi: 10.3390/cryst7070197

Studier, F. W. (2005). Protein production by auto-induction in high density shaking cultures. Protein Expr. Purif. 41, 207-234. doi: 10.1016/j.pep.2005.01.016

Suzuki, N., Hiraki, M., Yamada, Y., Matsugaki, N., Igarashi, N., Kato, R., et al. (2010). Crystallization of small proteins assisted by green fluorescent protein. Acta Crystallogr. Sect. D Biol. Crystallogr. 66, 1059-1066. doi: $10.1107 /$ S0907444910032944

Svergun, D. I. (1992). Determination of the regularization parameter in indirecttransform methods using perceptual criteria. J. Appl. Crystallogr. 25, 495-503. doi: $10.1107 /$ S0021889892001663
Svergun, D. I. (1999). Restoring low resolution structure of biological macromolecules from solution scattering using simulated annealing. Biophys. J. 76, 2879-2886. doi: 10.1016/S0006-3495(99)77443-6

Tuukkanen, A. T., Kleywegt, G. J., and Svergun, D. I. (2016). Resolution of ab initio shapes determined from small-angle scattering. IUCrJ. 3, 440-447. doi: $10.1107 /$ S2052252516016018

Uebe, R., Junge, K., Henn, V., Poxleitner, G., Katzmann, E., Plitzko, J. M., et al. (2011). The cation diffusion facilitator proteins MamB and MamM of Magnetospirillum gryphiswaldense have distinct and complex functions, and are involved in magnetite biomineralization and magnetosome membrane assembly. Mol. Microbiol. 82, 818-835. doi: 10.1111/j.1365-2958.2011.07863.x

Ullah, R., Shehzad, A., Shah, M. A., March, M., De, I.smat, and F., Iqbal, M., et al. (2020). C-terminal domain of the human zinc transporter hZnT8 is structurally indistinguishable from its disease risk variant (R325W). Int. J. Mol. Sci. 21:926. doi: 10.3390/ijms21030926

Uzdavinys, P., Coinçon, M., Nji, E., Ndi, M., Winkelmann, I., von Ballmoos, C., et al. (2017). Dissecting the proton transport pathway in electrogenic $\mathrm{Na}(+) / \mathrm{H}(+)$ antiporters. Proc. Natl. Acad. Sci. U. S. A. 114, E1101-E1110. doi: $10.1073 /$ pnas. 1614521114

Vallee, B. L., and Falchuk, K. H. (1993). The biochemical basis of zinc physiology. Physiol. Rev. 73, 79-118. doi: 10.1152/physrev.1993.73.1.79

Vieira Gomes, A., Souza Carmo, T., Silva Carvalho, L., Mendonça Bahia, F., and Parachin, N. (2018). Comparison of yeasts as hosts for recombinant protein production. Microorganisms 6:38. doi: 10.3390/microorganisms6020038

Volkov, V. V., and Svergun, D. I. (2003). Uniqueness of ab initio shape determination in small-angle scattering. J. Appl. Crystallogr. 860-864. doi: $10.1107 /$ S0021889803000268

Wei, Y., and Fu, D. (2005). Selective metal binding to a membrane-embedded aspartate in the Escherichia coli metal transporter YiiP (FieF). J. Biol. Chem. 280, 33716-33724. doi: 10.1074/jbc.M506107200

Whitten, A. E., Cai, S., and Trewhella, J. (2008). MULCh: Modules for the analysis of small-angle neutron contrast variation data from biomolecular assemblies. J. Appl. Crystallogr. 41, 222-226. doi: 10.1107/S0021889807055136

Xu, F., Wu, H., Katritch, V., Han, G. W., Jacobson, K. A., Gao, Z. G., et al. (2011). Structure of an agonist-bound human A2A adenosine receptor. Science 332, 322-327. doi: 10.1126/science. 1202793

Xu, T., Chen, H., Li, J., Hong, S., Shao, L., Zheng, X., et al. (2019). Implications for cation selectivity and evolution by a novel cation diffusion facilitator family member from the moderate halophile planococcus dechangensis. Front. Microbiol. 10:607. doi: 10.3389/fmicb.2019.00607

Xue, J., Xie, T., Zeng, W., Jiang, Y., and Bai, X. (2020). Cryo-EM structures of human ZnT8 in both outward- and inward-facing conformations. eLife 9:e58823. doi: 10.7554/eLife.58823

Yang, J., Yan, R., Roy, A., Xu, D., Poisson, J., and Zhang, Y. (2014). The ITASSER suite: protein structure and function prediction. Nat. Methods 12, 7-8. doi: 10.1038/nmeth.3213

Zeytuni, N., Uebe, R., Maes, M., Davidov, G., Baram, M., Raschdorf, O., et al. (2014). Cation diffusion facilitators transport initiation and regulation is mediated by cation induced conformational changes of the cytoplasmic domain. PLoS ONE 9:e92141. doi: 10.1371/journal.pone. 0092141

Conflict of Interest: The authors declare that the research was conducted in the absence of any commercial or financial relationships that could be construed as a potential conflict of interest.

Copyright $(0) 2021$ Cotrim, Jarrott, Whitten, Choudhury, Drew and Martin. This is an open-access article distributed under the terms of the Creative Commons Attribution License (CC BY). The use, distribution or reproduction in other forums is permitted, provided the original author(s) and the copyright owner(s) are credited and that the original publication in this journal is cited, in accordance with accepted academic practice. No use, distribution or reproduction is permitted which does not comply with these terms. 